
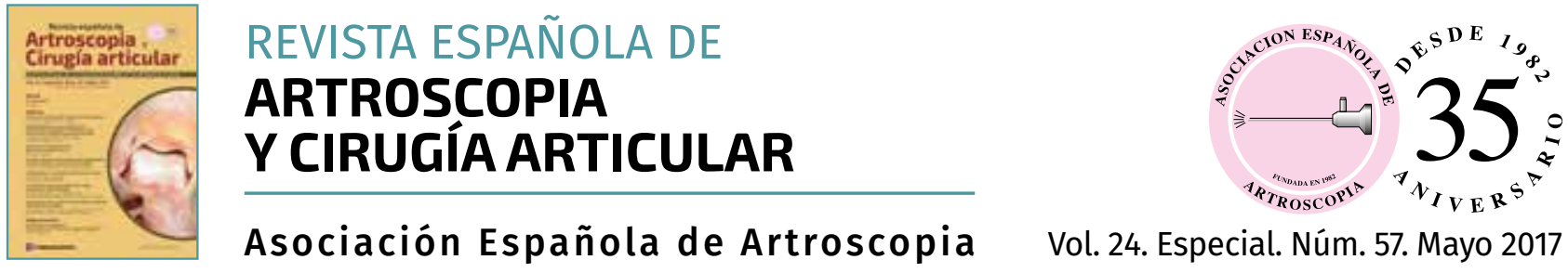

\title{
Original
}

\section{5 años de la Asociación Española de Artroscopia}

\author{
R. Seijas ${ }^{1,2}$, R. Cuéllar ${ }^{3}$, M. García ${ }^{1,4}$, R. Cugat ${ }^{1,4,5}$ \\ ${ }^{1}$ Fundación García Cugat. Hospital Quirónsalud Barcelona \\ 2 Universidad Internacional de Catalunya. Barcelona \\ ${ }^{3}$ Hospital Universitario Donostia. San Sebastián \\ ${ }^{4}$ Cátedra de Medicina y Cirugía Regenerativa. Universidad CEU Cardenal Herrera. Valencia \\ ${ }^{5}$ Mutualidad de Futbolistas de la Real Federación Española de Fútbol
}

Correspondencia:

Dr. Roberto Seijas Vázquez

Correo electrónico: seijastraumatologia@gmail.com
Recibido el 5 de marzo de 2017

Aceptado el 5 de marzo de 2017

Disponible en Internet: mayo de 2017

\section{RESUMEN}

Hace 10 años, en la celebración del 25 aniversario de la creación de la Asociación Española de Artroscopia (AEA), dos de las figuras más importantes y partícipes en la creación de la asociación, los Dres. Montserrat García y Ramón Cugat, nos ofrecieron un repaso histórico del primer cuarto de siglo de historia de nuestra sociedad.

Como celebración de los 35 años de la creación de la AEA, con el impulso de nuestro actual presidente, hemos querido recuperar aquel artículo y ampliarlo en los siguientes 10 años, para recordar nuestro pasado y guiarnos en nuestro presente. Conocer nuestros orígenes y realizar este recorrido histórico nos permite una buena perspectiva que estamos seguros que nos dará un mejor punto de vista de nuestra propia asociación.

Palabras clave: Historia. Asociación Española de Artroscopia.

Hace ya 10 años que dos de los pilares en la creación y difusión de nuestra asociación nos relataron la historia de las bodas de plata entre la técnica artroscópica y los especialistas de la ar-

\begin{abstract}
35 years of the Arthroscopy Spanish Society

Ten years ago, in celebration of the $25^{\text {th }}$ anniversary of the creation of the Spanish Association of Arthroscopy (AEA), two of the most important figures and participants in the creation of the association, Drs. Montserrat García and Ramón Cugat, offered us a historical review of the first quarter century of our society's history.

As a celebration of the $35^{\text {th }}$ anniversary of the creation of the AEA, with the encouragement of our current president, we wanted to recover that article and expand it in the next 10 years, to remember our past and guide us in our present. Knowing our origins and realizing this historical journey allows us a good perspective that we are sure will give us a better point of view of our own association.
\end{abstract}

Key words: History. Spanish Association of Arthroscopy.

ticulación. El trabajo constante y el perenne entusiasmo han hecho de ellos una fuente de conocimiento y de experiencia siempre regados de una actitud proactiva hacia la expansión del co-

https://doi.org/10.24129/j.reaca.24e57.fs1702008

FS $₫ 2017$ Fundación Española de Artroscopia. Publicado por Imaidea Interactiva en FONDOSCIENCE ${ }^{\circledR}$ (www.fondoscience.com). Este es un artículo Open Access bajo la licencia CC BY-NC-ND (www.creativecommons.org/licenses/by-nc-nd/4.0/). 
nocimiento. El papel de los Dres. Montserrat García y Ramón Cugat fue esencial para la creación en 1982 de la Asociación Española de Artroscopia (AEA), con la presidencia del Dr. José García Cugat, padre y suegro de aquellos.

En el 25 aniversario de la creación de la AEA, la revista Cuadernos de Artroscopia publicó un extenso resumen de la historia común plagada de nombres, lugares y experiencias, fruto de la experiencia acumulada de estos dos padres de toda una generación de especialistas en artroscopia. En la actualidad, al celebrarse los 35 años de la creación de nuestra asociación, queremos ampliar el relato de aquella historia, para que recordar nuestro pasado nos sirva de experiencia y sepa guiarnos en nuestro presente, con la mejor actitud, para llenar nuestro futuro de conocimiento.

Por ello, en estas líneas reproducimos aquella publicación y continuamos, después de 25 años, con los siguientes 10 años...

\section{Prehistoria}

Algunos años después de que el danés Severin Nordentoft presentase durante el transcurso de 1912 ante la Sociedad Alemana de Cirugía el primer trabajo de "visión de una cavidad articular valiéndose de un instrumento óptico"; de que el japonés Kenji Takagi en 1918 hiciese la primera artroscopia en rodilla de cadáver; y de que el suizo Eugen Bircher el año siguiente siguiera los mismos pasos, la artroscopia llegó a España por primera vez (Figura 1).

Durante el año 1957, en Barcelona se celebró el VII Congreso SICOT (Société Internationale de Chirurgie Orthopédique et de Traumatologie) y el japonés diseñador del "artroscopio Watana-

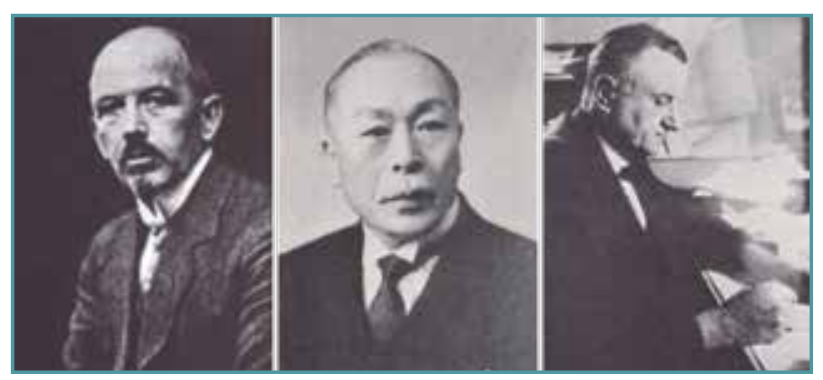

Figura 1. De izda. a dcha., Severin Nordentoft, Kenji Takagi y Eugen Bircher.

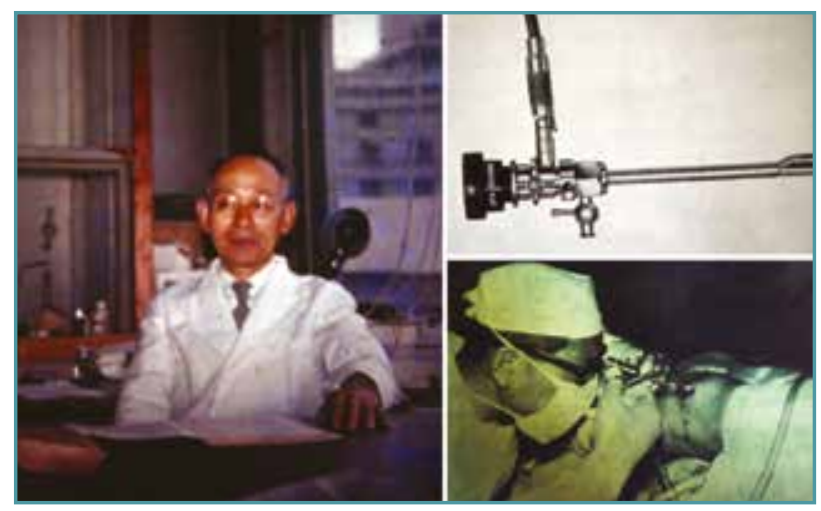

Figura 2. Masaki Watanabe, diseñador del artroscopio Watanabe 21. Inició la cirugía artroscópica el 9 de marzo de 1955. Presentó una película titulada Arthroscopy of the knee joint en el VII Congreso de SICOT celebrado en Barcelona en 1957. Realizó la 1.a meniscectomía artroscópica el 4 de mayo de 1962.

be 21", base de los artroscopios actuales, Masaki Watanabe, presentó una película titulada Arthroscopy of the knee joint (Figura 2).

Sin embargo, en esos momentos la artroscopia no era una técnica habitual en los servicios de cirugía ortopédica y traumatología. Por el contrario, los reumatólogos se servían de la técnica para estudiar la sinovial articular. Los que más destacaron fueron J. Marqués, P. Barceló y G. Gómez Martínez, todos ellos reumatólogos del Centro Nacional de la Lucha contra las Enfermedades Reumáticas de Barcelona, que en su práctica diaria realizaban artroscopia diagnóstica en las rodillas de sus pacientes. Esto ocurría en 1970, y en 1977 publicaron el libro La artroscopia.

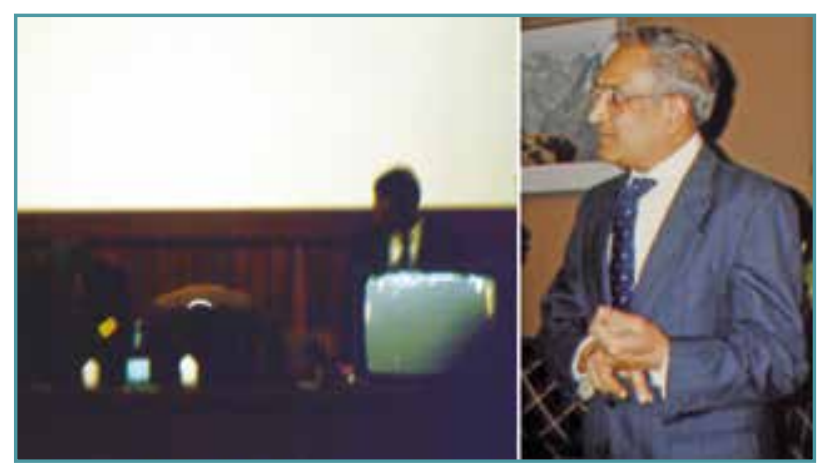

Figura 3. I Reunión de Artroscopia celebrada en Barcelona a principios de los años ochenta. Organizador: José M.a Figueras. Profesor invitado: Dinesh Patel, Boston, Massachusetts, EE.UU. 


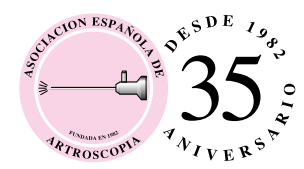

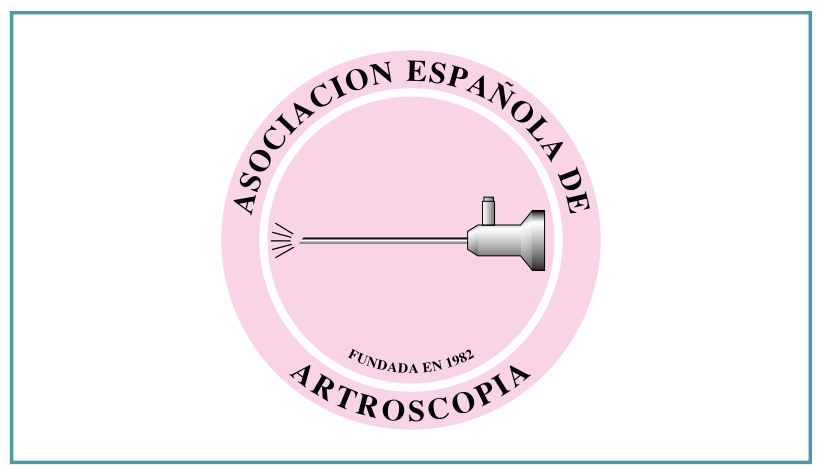

Figura 4. La Asociación Española de Artroscopia se fundó el día 6 de febrero de 1982.

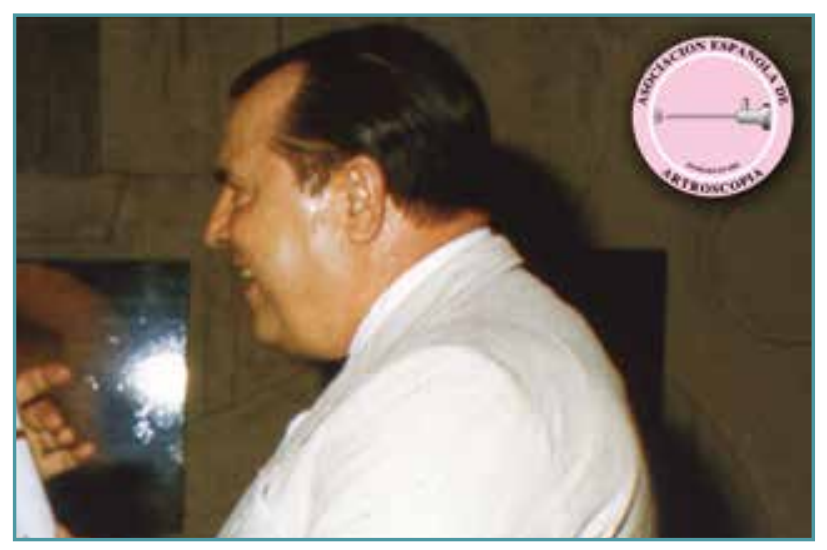

Figura 5. José García Cugat (Barcelona, 1982-1983), presidente fundacional. Finalidades: 1) enseñar artroscopia en todo el país; 2) celebrar un congreso anual; 3) publicar una revista.

Cuando a finales de los setenta eclosionó España, la formación de posgrado se expandió fuera de las fronteras y los cirujanos ortopedas iniciaron el aprendizaje de la cirugía artroscópica.

El I Curso Teórico-Práctico de Artroscopia de Rodilla se celebró durante los días 27 y 28 de noviembre de 1981 en el Hospital de la Cruz Roja de Barcelona. El comité organizador estaba formado por: José M.a Figueras, Merino, Miguel Llobet y Félix Escalas. El profesor invitado fue Dinesh Patel, del Massachusetts General Hospital, Harvard University, Boston (Figura 3).

\section{Historia}

Meses después del mencionado curso, se fundó la AEA. Fue el 6 de febrero de 1982, siendo el

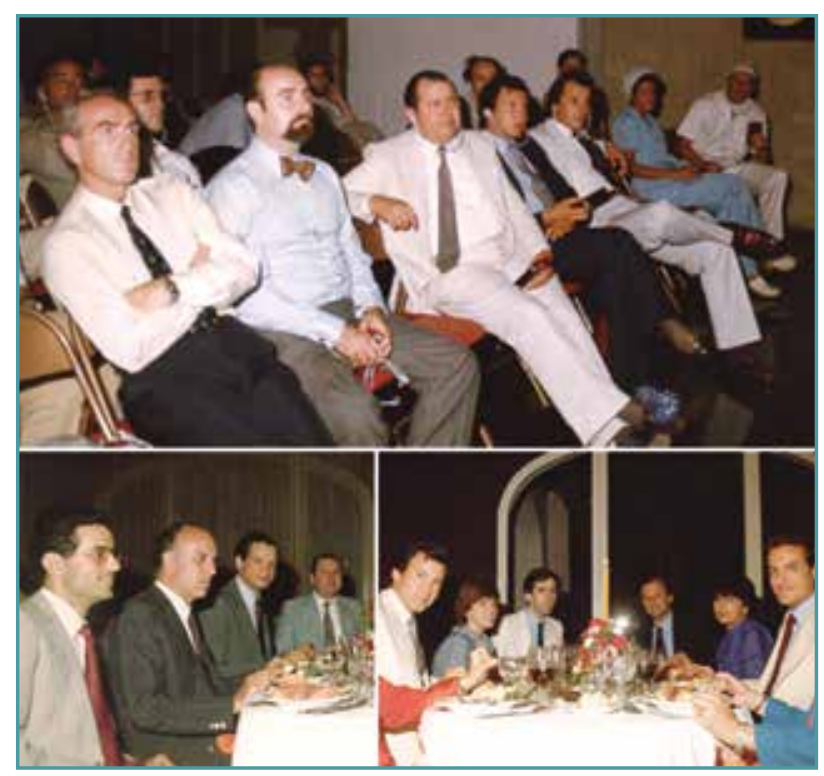

Figura 6. I Congreso Nacional de la Asociación Española de Artroscopia.

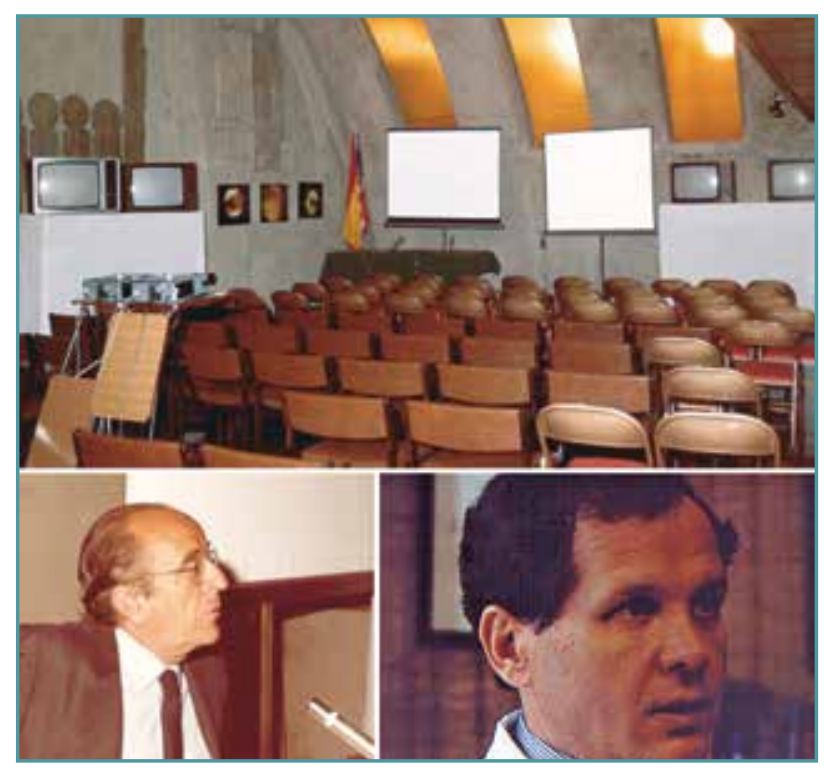

Figura 7. Arriba: aspecto que ofrecía la sala de conferencias momentos antes de iniciarse el I Congreso de la Asociación Española de Artroscopia. El Conseller de Sanitat realizó la inauguración oficial (abajo izda.) y el profesor invitado fue Bertram Zarins (Boston, Massachusetts, EE.UU.) (abajo dcha.).

presidente fundador José García Cugat, que ostentó el cargo hasta 1983. Se fijaron 3 objetivos: enseñar artroscopia a toda España, celebrar un congreso anual y editar una revista propia (Figuras 4 y 5). El 


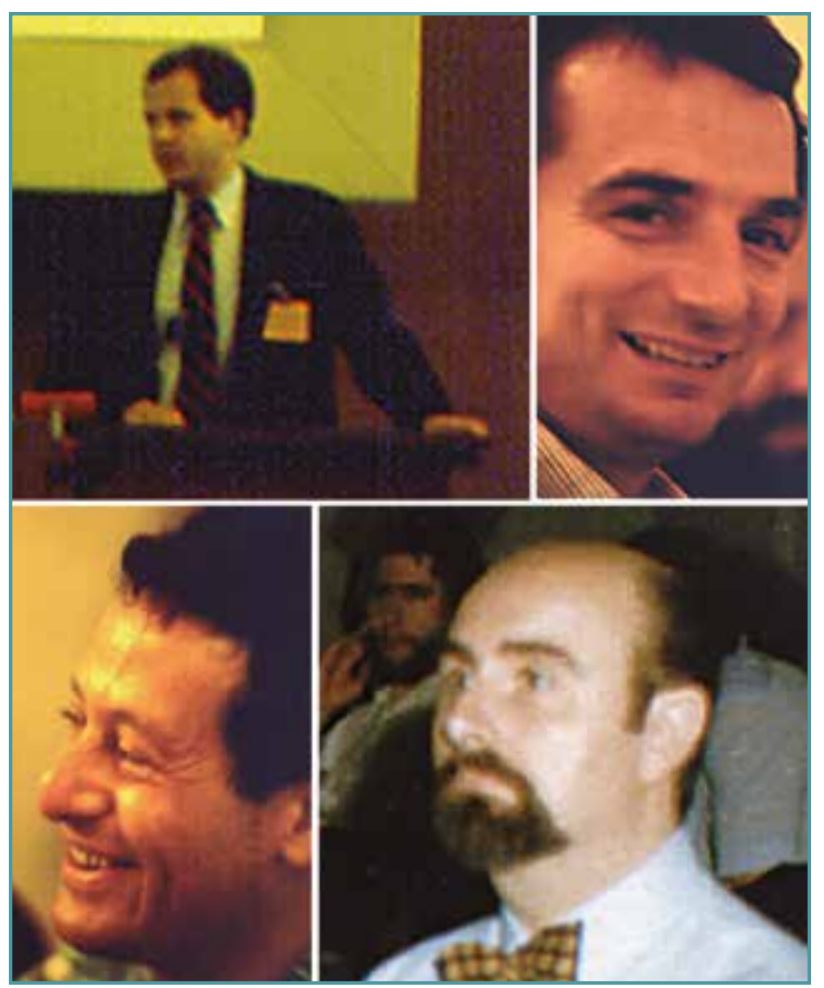

Figura 8. De izda. a dcha. y de arriba abajo, Bertram Zarins (EE.UU.), Pierre Sagnet (Francia), Krzentowsky (Francia) y Luis Munuera Martínez, nuevo presidente electo (1983-1987).

primer congreso nacional se celebró los días 8 y 9 de junio en la ciudad de Barcelona, siendo el profesor invitado Bertram Zarins, también del Massachusetts General Hospital, Harvard University, Boston. Bertram Zarins fue nombrado Presidente de Honor de la Sociedad, ya que fue el impulsor de la creación de ella (Figuras 6 y 7).

El Il congreso se celebró en Madrid el año 1983. El organizador, profesor D. Luis Munuera Martínez, fue nombrado presidente y ostentó el cargo hasta 1987. En esta ocasión, los profesores invitados fueron: de nuevo Bertram Zarins; Frizzero, de Italia; Pierre Sagnet y Krzentowsky, de París, Francia (Figura 8).

El III congreso se volvió a celebrar en Barcelona el año 1984. El organizador fue Joaquín Cabot y repitieron como profesores invitados Pierre Sagnet y Krzentowsky, ambos de París (Figura 9).

Durante el transcurso de 1984 se celebró el I Congreso de la ESSKA (European Society of Sports Medicine, Knee Surgery and Arthroscopy) en Berlín, Alemania, siendo el presidente funda-
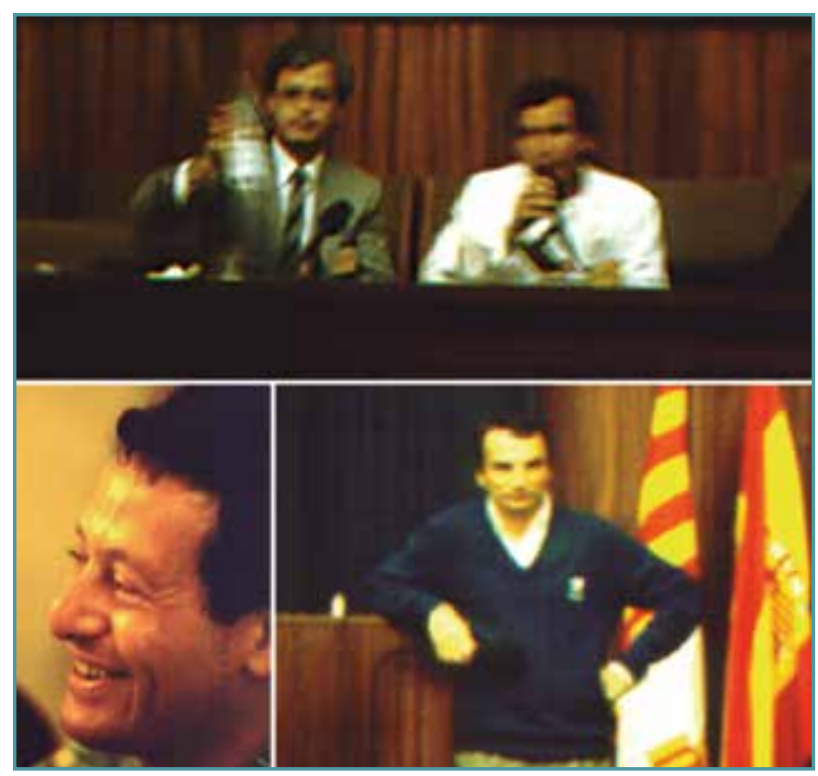

Figura 9. De izda. a dcha. y de arriba abajo, Dr. Llobet y Dr. Joaquín Cabot (organizador). Profesores invitados: Dres. Krzentowsky y Pierre Sagnet (Francia).
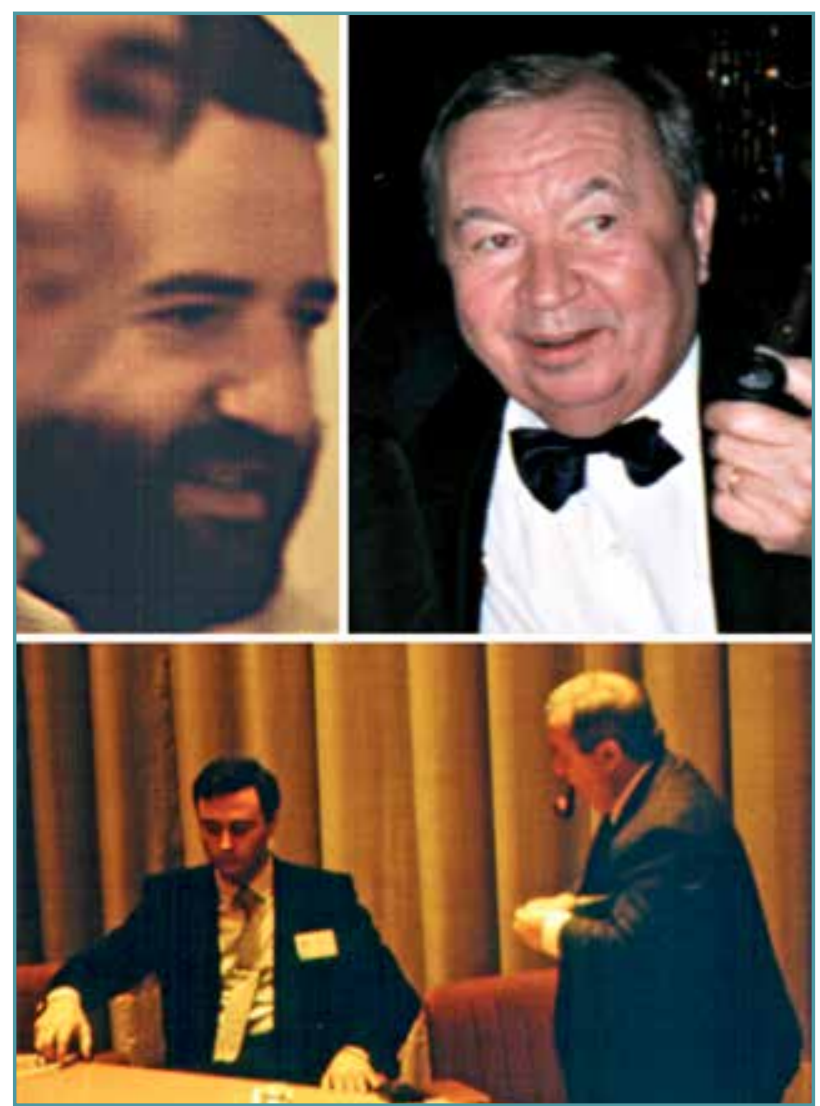

Figura 10. De izda. a dcha. y de arriba abajo, Dr. José Achalandabaso (organizador). Profesores invitados: Dr. Jacquie Defrere (Bélgica) y Dres. Burgos y Ocete (España). 


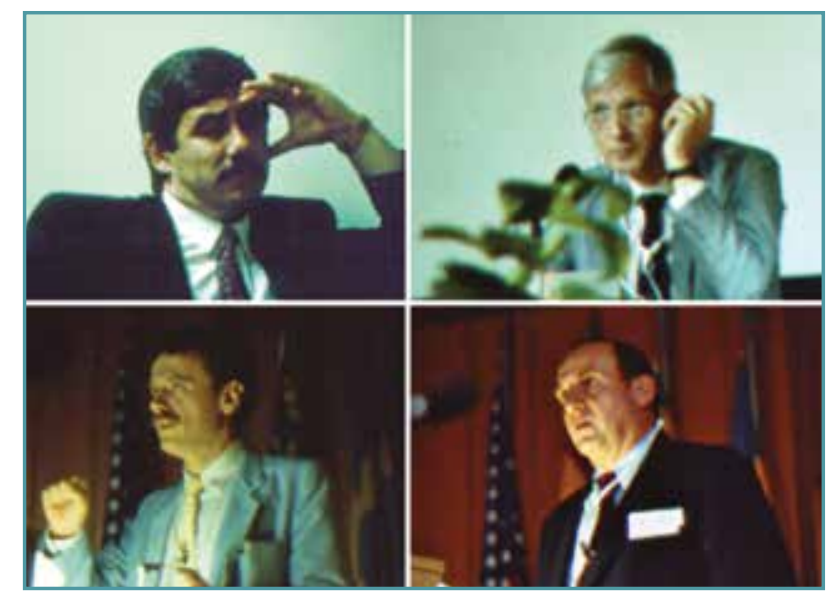

Figura 11. De izda. a dcha. y de arriba abajo, Dr. Eduardo López Vázquez (organizador). Profesores invitados: Dres. Jan Gillquist y Lysholm (Suecia), Dr. Kenneth DeHaven (EE.UU.).

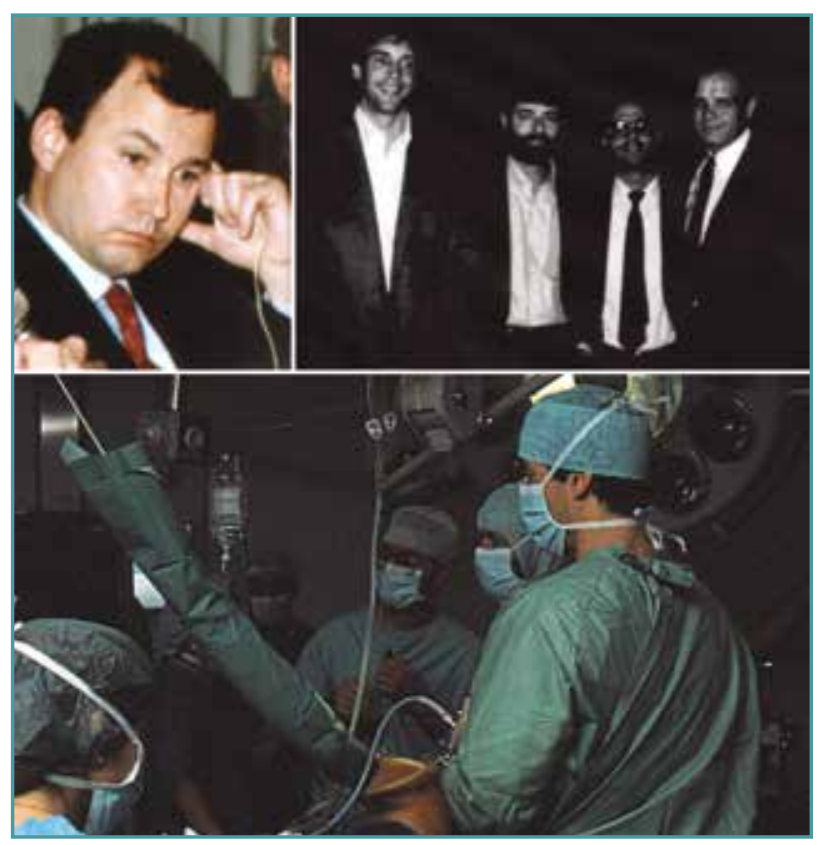

Figura 12. De izda. a dcha. y de arriba abajo, Dr. Joaquín Cabot, nuevo presidente electo. Dres. Edward Tillet, Richard B. Caspari, Ramón Cugat, Bertram Zarins y Robert Metcalf (EE.UU.). La cirugía en directo fue realizada por los Dres. Caspari y Tillet. Se intervino un hombro.

cional de dicha sociedad el profesor Ejnar Eriksson, de Estocolmo, Suecia.

El IV congreso se celebró en San Sebastián el año 1985. En esta ocasión, el organizador fue José Achalandabaso y los profesores invita-

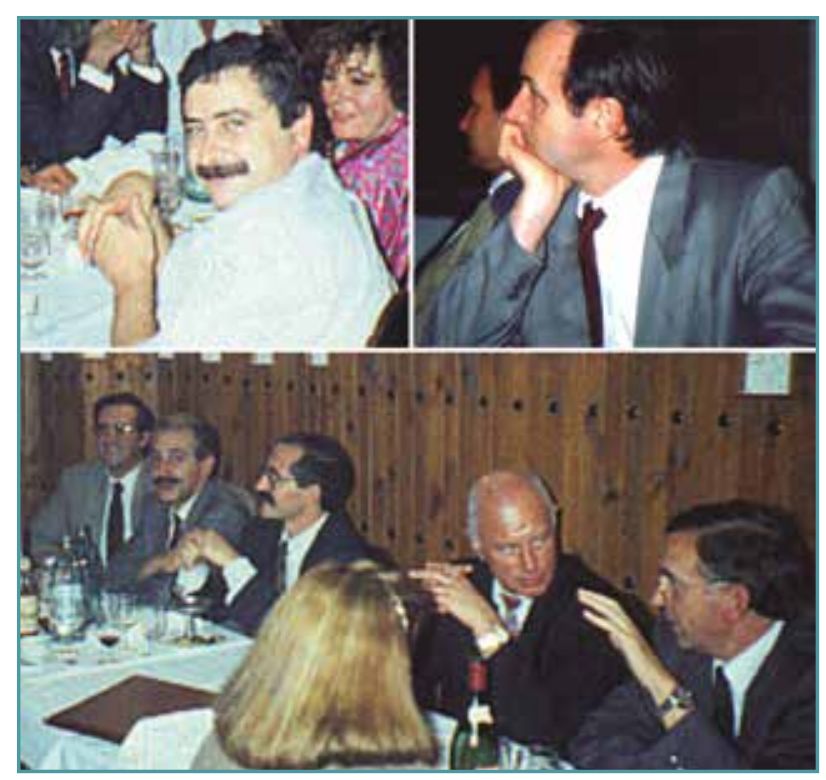

Figura 13. De izda. a dcha. y de arriba abajo, Dr. José M.a Cortés Vida (organizador). Profesores invitados: Dr. Pierre Chambat (Francia) y Dr. Jurgen Toft (Alemania).

dos fueron Richard Hawkins, de EE. UU.; Burgos y Ocete, de Madrid; y Jacquie Defrere, de Lieja, Bélgica (Figura 10).

El V congreso se celebró en 1986 en la ciudad de Sagunto, Valencia. En esta ocasión el organizador fue Eduardo López Vázquez y los profesores invitados fueron del Instituto Karolinska, de Estocolmo, Jan Gillquist y Lysholm, y Kenneth DeHaven, de la Mayo Clinic, Rochester University, Rochester, EE. UU. (Figura 11).

El VI congreso se celebró en 1987 en Granada, organizado por el Dr. Luis Roca, y los profesores invitados fueron los norteamericanos Bertram Zarins de Boston, que ya era conocido por la sociedad; Richard B. Caspari, de Richmond; Edward Tillet, de Kentucky; y Robert Metcalf, de Salt Lake City, que no pudo participar por sufrir un agravamiento de la artritis reumatoide que padecía. Se realizó una cirugía en directo: una estabilización artroscópica de hombro llevada a cabo por los Dres. Caspari y Tillet. En esa ocasión, hubo renovación de la presidencia, cesó Luis Munuera y fue elegido Joaquín Cabot (Figura 12).

El VII congreso se celebró en 1988 en Badajoz. El Dr. José M. a Cortés Vida fue el organizador y los profesores invitados fueron el Dr. Pierre Chambat, de Lyon, Francia; y el Dr. Jurgen Toft, de Múnich, Alemania (Figura 13). 


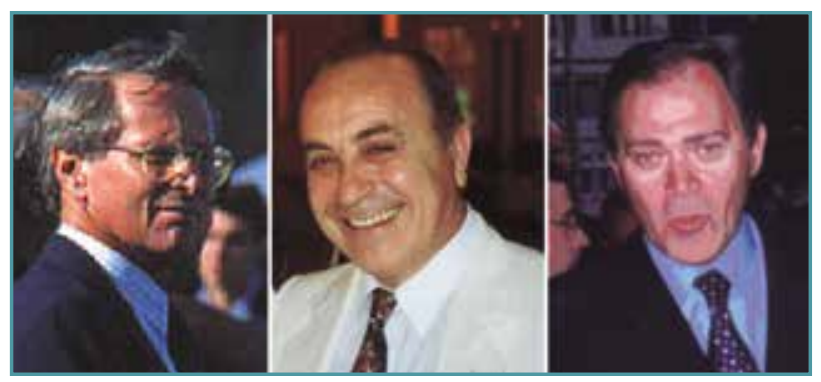

Figura 14. De izda. a dcha., Dr. Richard Levitt (EE.UU.), Dr. Leandro Ranaletta (Argentina) y Dr. José Luis Aparici (Argentina).

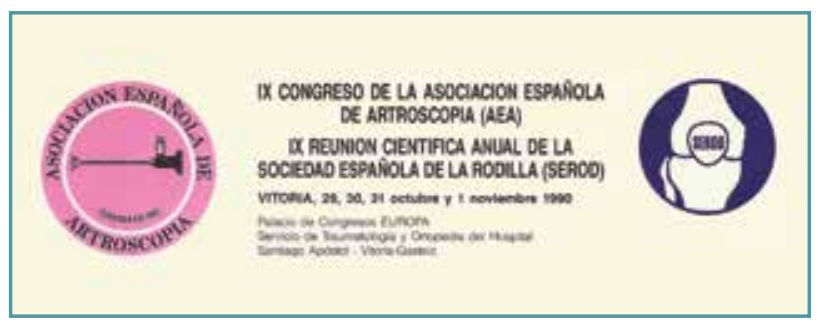

Figura 15. IX Congreso de la Asociación Española de Artroscopia.

En el transcurso de 1988 se llevó a término el I Curso de Docencia con Especímenes Congelados en el Laboratorio del Departamento de Anatomía Humana, a cargo del profesor Domingo Ruano Gil, en la Facultad de Medicina de la Universidad de Barcelona.

El VIII congreso se celebró en la ciudad de Gijón, Asturias, el año 1989. Antonio Murcia y Francisco Javier Palacio fueron los organizadores y los profesores invitados el estadounidense Richard Levitt, de Miami, y los argentinos Leandro Ranaletta, de La Plata, y José Luis Aparici, de Rosario (Figura 14).

El IX congreso se celebró en Vitoria el año siguiente, 1990 (Figura 15). El organizador fue Mikel Sánchez y los profesores invitados Fujikawa, de Japón, Edward Bittar, de los EE.UU., y los franceses Gilles Walch, de Lyon, y Pascal Boileau, de Niza. En aquella ocasión se celebró realmente por primera vez un congreso conjunto entre la AEA y la SEROD (Sociedad Española de la Rodilla), aunque de forma consecutiva y no simultánea durante los días 29 de octubre al 1 de noviembre. Eran los presidentes Joaquín Cabot, por parte de la AEA, y Manuel Marín, por parte de la SEROD (Figura 16).
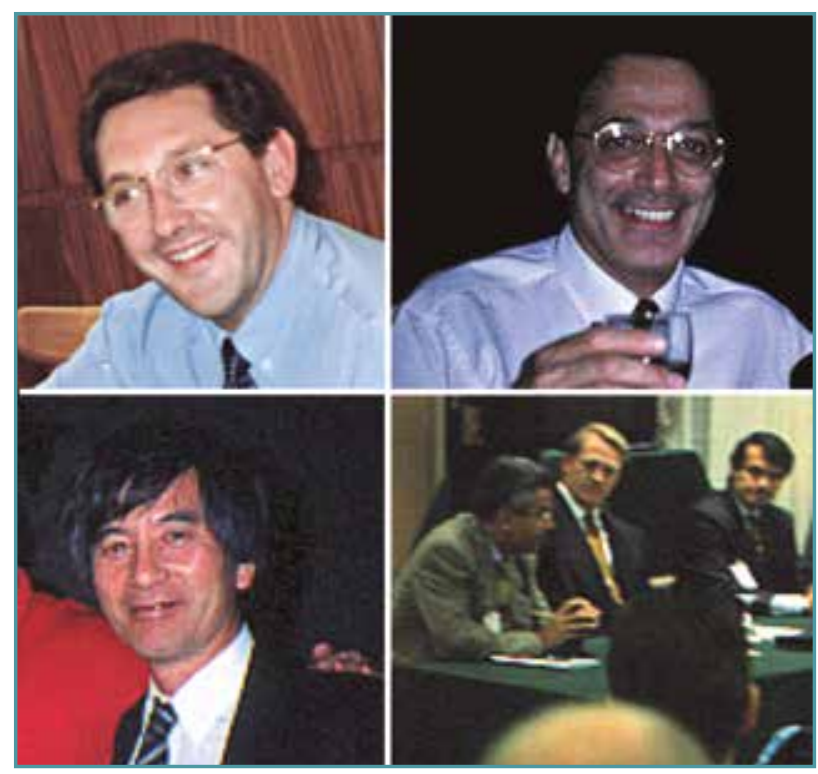

Figura 16. De izda. a dcha., Dr. Mikel Sánchez (organizador). Profesores invitados: Dr. Edward Bittar (EE.UU.), Dr. Fujikawa (Japón), Dr. E. Walch (Francia).

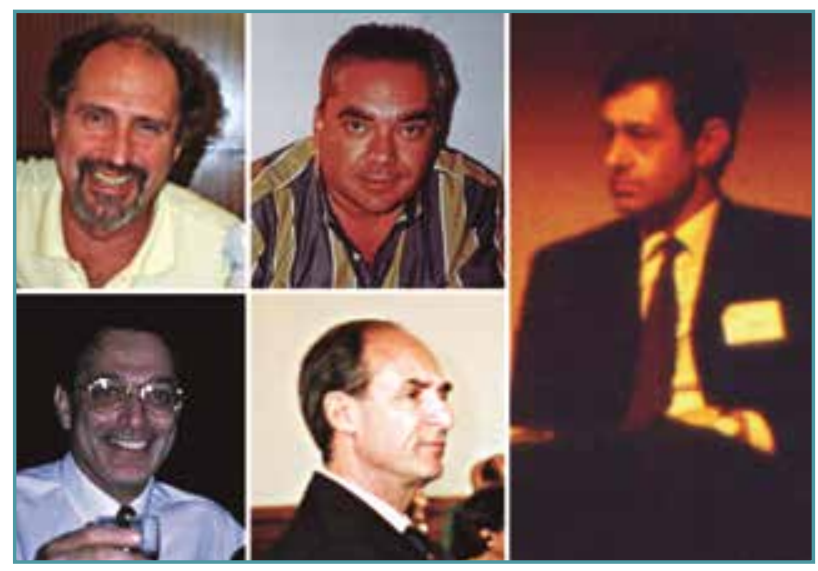

Figura 17. De izda. a dcha., Dr. Raúl Puig (nuevo presidente electo), Manuel Baro (organizador). Profesores invitados: Dr. David J. Dandy (EE.UU.), Dr. Edward Bittar (EE.UU.), Dr. Enri Dorfmann (Francia).

El X congreso se celebró en la isla canaria de Santa Cruz de Tenerife los días 21 a 24 de octubre de 1991. Manuel Baro fue el organizador, junto con Mario Montequi, Harry Friend, Rodríguez, Brito, Martín-Lanzone, González Massieu y Herrera. Los profesores invitados fueron el estadounidense Edward Bittar de nuevo, Henri Dorfmann, de Paris, y David Dandy, de Cambridge, Reino Unido. Durante su transcurso hubo renovación de la pre- 


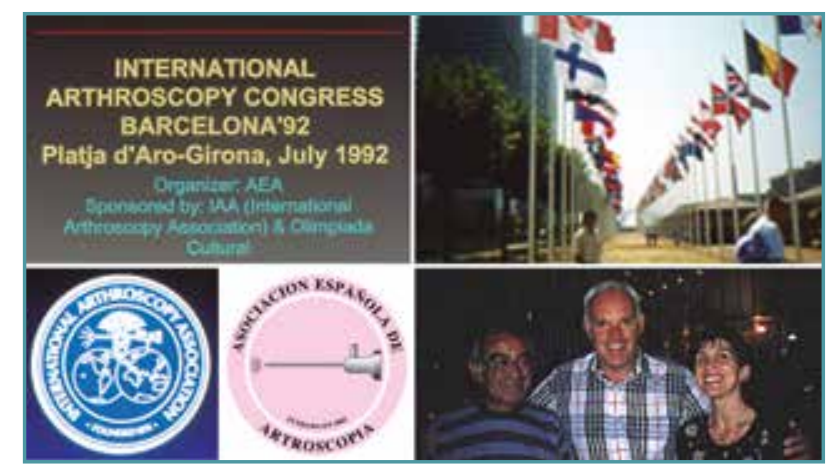

Figura 18. International Arthroscopy Congress Barcelona'92.

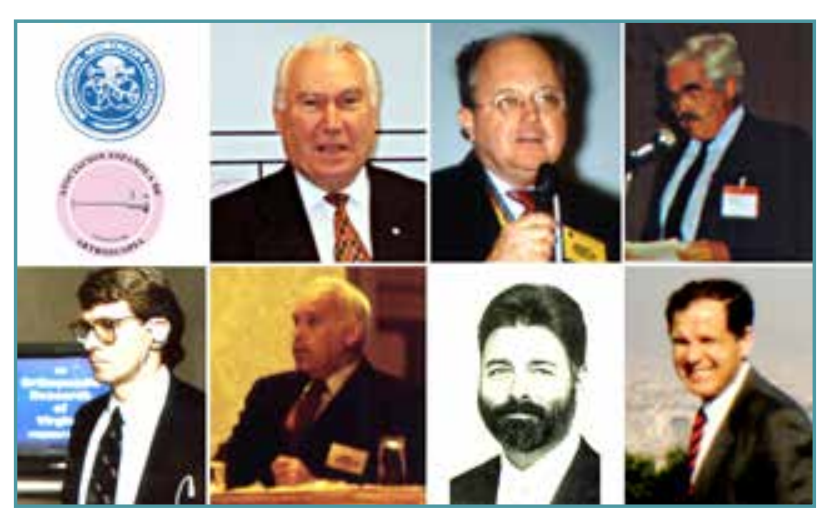

Figura 19. De izda. a dcha., profesores invitados de los EE. UU.: Dr. R. Jackson, Dr. H. Sweeny, Dr. J. McGinty, Dr. T. Whipple, Dr. L. Johnson, Dr. R. Caspari y Dr. B. Zarins.

sidencia, siendo elegido Raúl Puig, que ostentó el cargo hasta 1993 (Figura 17).

En 1992 la AEA celebró su décimo aniversario. La "onomástica" coincidió con la celebración de los Juegos Olímpicos de Barcelona y fue el año en que se "internacionalizó". El congreso anual no se denominó con el número de orden que le correspondía, sino que fue el International Arthroscopy Congress Barcelona'92. Se celebró en Platja D’Aro, Girona, en el mes de julio, los días previos a la ceremonia inaugural de los juegos (Figura 18). Los organizadores fueron Joaquín Cabot, Ramón Cugat y Miguel Llobet. Estuvo patrocinado por la IAA (International Arthroscopy Association) y por la Olimpiada Cultural. Los profesores invitados fueron Robert Jackson, que en aquellos momentos estaba trasladándose de Toronto, Canadá, a Dallas, EE.UU., por lo que se ausentó; los estadounidenses Howard Sweeny, John B. McGinty, Terry Whipple, Lanny Johnson, Richard Caspari y

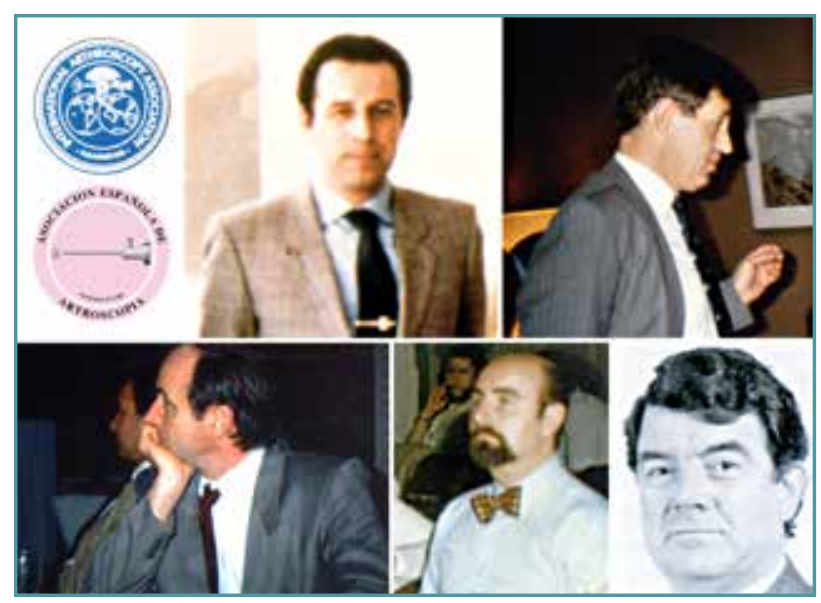

Figura 20. De izda. a dcha., profesores invitados de Europa: Dr. Paolo Aglietti (Italia), Dr. David Dandy (Reino Unido), Dr. Pierre Chambat (Francia), Dr. Luis Munuera (España). Profesor invitado de Oceanía: David J. Marshall (Australia).

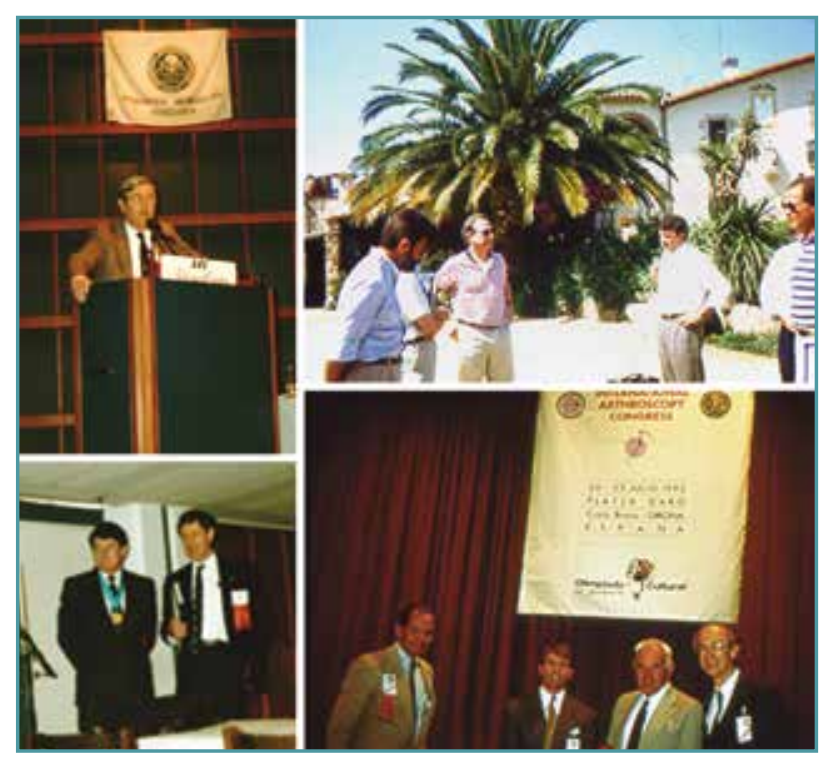

Figura 21. Congreso Internacional de Artroscopia Barcelona'92.

Bertram Zarins; Luis Munuera, de Madrid; Paolo Aglietti, de Florencia; Pierre Chambat, de Lyon; David Dandy, de Cambridge, expresidente inmediato de la IAA; Harold Eikelaar, de Groningen, primer vicepresidente de la IAA; y David Marshall, de Adelaida, Australia, presidente de la IAA. La comunidad internacional de artroscopia fue sabedora de este evento, por lo que hubo participantes y asistentes de todos los continentes. A partir 


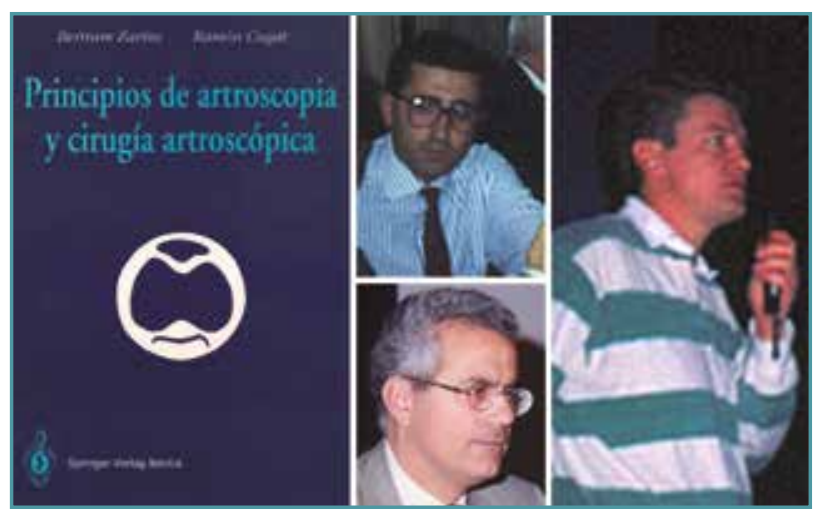

Figura 22. XI Congreso de la Asociación Española de Artroscopia. De izda. a dcha. y de arriba abajo, Dr. Manuel Díaz Samada (organizador); nuevo presidente electo: Dr. Ramón Cugat; profesor invitado: Dr. D. Mole (Francia).

de ese momento, la AEA ha patrocinado multitud de congresos, cursos y reuniones celebradas en España (Figuras 19, 20 y 21).

El XI congreso se celebró los días 30 de septiembre y 1 y 2 de octubre de 1993 en Marbella, Málaga. Manuel Díaz Samada fue el organizador, junto con los doctores Ferrer Lariño y Pascual Codeso. Los profesores invitados fueron el francés Michel Allard, de Burdeos; el austriaco Herbert Resch, de Salzburgo; y el estadounidense Eugen Wolf, de San Francisco (Figura 22). A la par, se celebró el I Curso de Instrumentación en Artroscopia para Enfermería. En esa ocasión, se acordó la creación de las corresponsalías autonómicas como organismos vectores del grupo de cirujanos que practican la técnica artroscópica en una comunidad, para acercar, de esta forma, la directiva de la asociación a todos sus miembros; y salió a la luz el número 0 de los Cuadernos de Artroscopia, la revista de la asociación. También hubo renovación de la presidencia, siendo elegido Ramón Cugat, que ostentó el cargo hasta 1995. Springer-Verlag publicó el libro de Zarins y Cugat titulado Principios de Artroscopia y Cirugía Artroscópica, escrito en lengua española por múltiples autores de diferentes nacionalidades pero muchos de ellos miembros de la AEA.

La biblioteca y la videoteca de la asociación, que tienen sede en Madrid, también se gestaron ese año. En el año que nos ocupa, 1993, la AEA participó en el Meeting de Sociedades celebrado durante el Combined Congress'93 de la IAA y de la
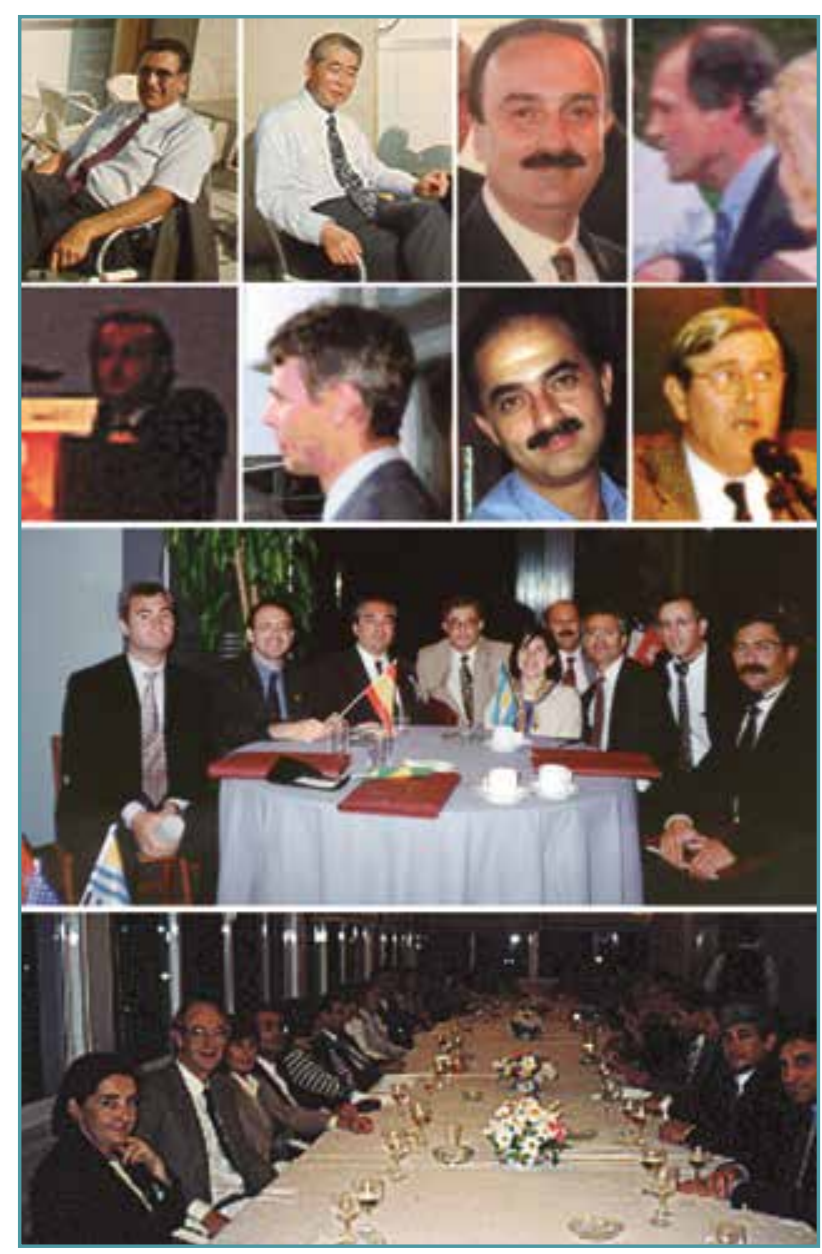

Figura 23. Participación de la Asociación Española de Artroscopia en el I Encuentro Latinoamericano, Buenos Aires, Argentina. De izda. a dcha. y de arriba abajo, Dr. Félix Pons (organizador), Dr. Hiroshi Ikeuchi (Japón), Dr. G. Cerulli (Italia), Dr. P. Benedetto (Austria), Dr. Christopher Constant (Reino Unido), Dr. P. Baufils (Francia), Dr. M. Doral (Turquía), Dr. H. Eikelar (Holanda).

IKS (International Knee Society) que tuvo lugar en Copenhague, Dinamarca.

El XII congreso se celebró en Palma de Mallorca los días 12, 13, 14 y 15 de octubre de 1994. El comité organizador estuvo presidido por Félix Pons Delgado. Los otros componentes fueron Alba Vidal, Sanguino Vidal, Ramos Martín y Martínez Muñoz. Los profesores invitados fueron Philippe Beaufils, de Versailles; Karl Peter Benedetto, de Innsbruck; Giuliano Cerulli, de Asís; Christopher Constant, de Cambridge; Harold Eikelaar, de Holanda, presidente de la IAA; y Mahmut Nemin Doral, de Ankara. Paralelamente, se celebró el 


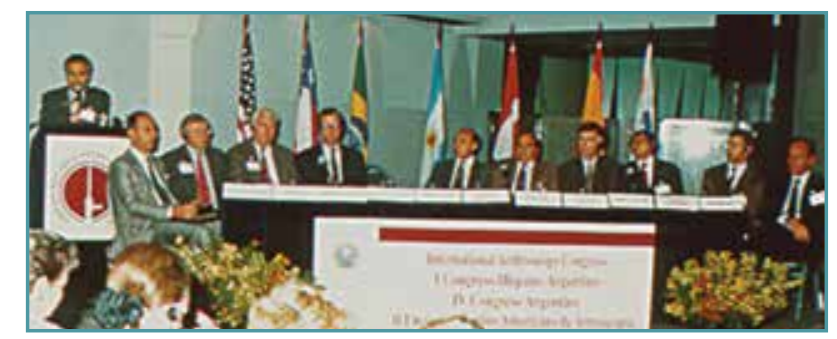

Figura 24. I Encuentro Latinoamericano, Buenos Aires.

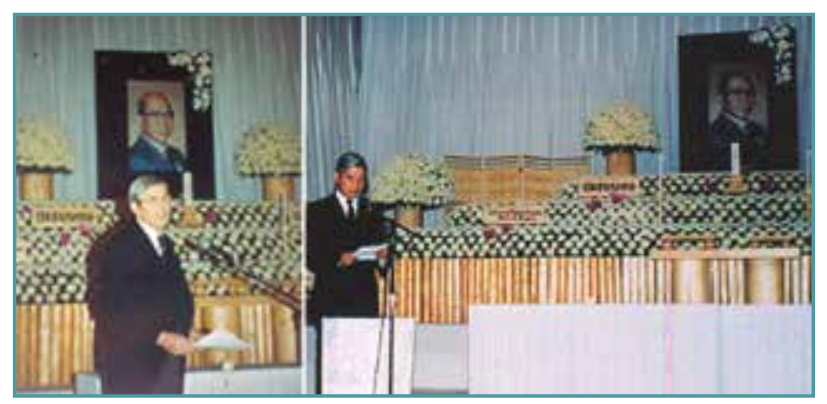

Figura 25. Funeral del Dr. Masaki Watanabe. Izda., Prof. Harol Eikelaar, presidente de la International Arthroscopy Association; dcha., Prof. Moriya.

Il Curso de Instrumentación en Artroscopia en Enfermería. En esa ocasión, hubo un participante insigne, el Dr. Hiroshi Ikeuchi, de Kawasaki, Japón (Figura 23). A lo largo de este año 1994, la AEA participó en el I Encuentro Latinoamericano celebrado en Buenos Aires, Argentina, durante el mes de abril y también tuvo presencia en el funeral del Dr. Masaki Watanabe, que falleció el mes de octubre (Figuras 24 y 25).

El XIII congreso se celebró en A Coruña los días 21, 22 y 23 de septiembre de 1995. Los organizadores fueron los doctores Fernández Gilino, Arriaza Loureda, González Canedo y Sampedro Curbera, mientras que los profesores invitados fueron los estadounidenses Abrams, Austin, Detrisac y McGuire; los alemanes Hans Päesler, Jäeger, Andre Bauer y Lehman; el entonces presidente de la sociedad francesa de artroscopia Andre Frank; y de Gran Bretaña, Villar. A la par también se celebró el III curso de enfermería. Durante este congreso volvió a haber cambio de presidencia, cesando Ramon Cugat y siendo elegido Juan José Rey, que ostentó el cargo hasta 1997 (Figuras 26 y 27).

En el transcurso de 1995 y tras celebrarse el Congreso bianual de la IAA y la IKS, cuyos presidentes eran el holandés Harold Eikelaar de la

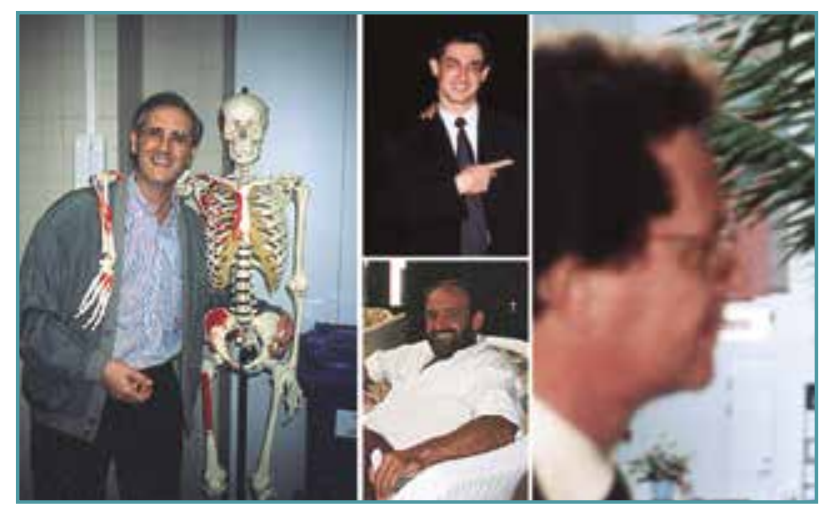

Figura 26. XIII Congreso de la Asociación Española de Artroscopia, A Coruña. De izda. a dcha. y de arriba abajo, Dr. Juan José Rey (nuevo presidente electo), Dres. Arriaza Loureda y Fernández Gilino (organizadores). Profesor invitado: Dr. Andre Frank (Francia).

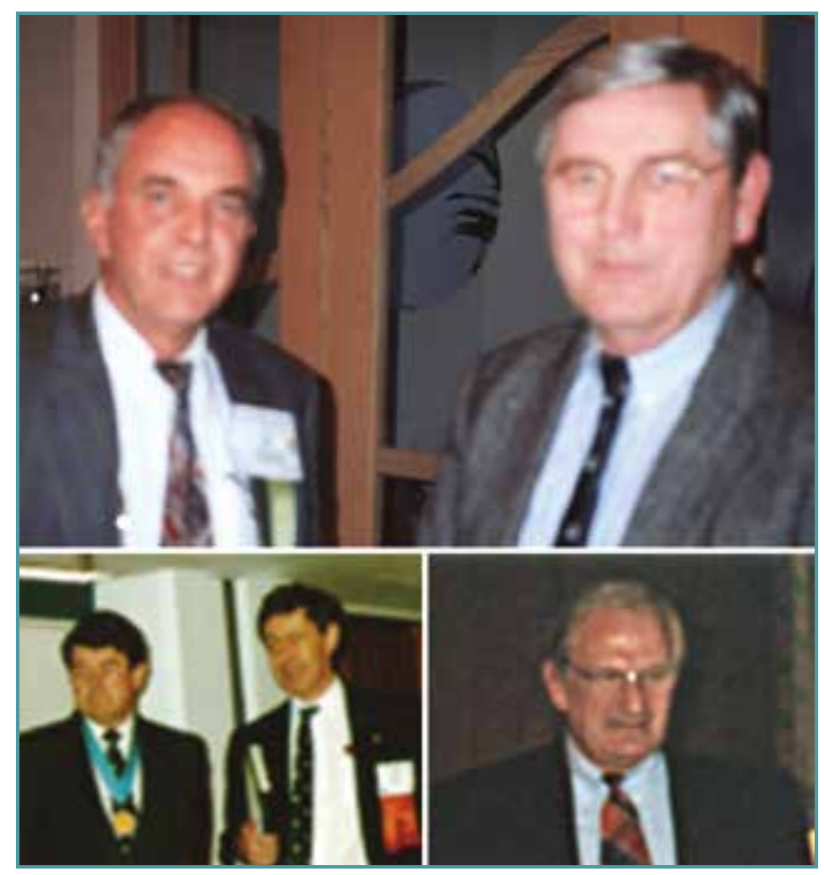

Figura 27. Arriba, Dr. René Martin (último presidente de la International Knee Society, Holanda) y Dr. Harold Eikelar (último presidente de la International Arthroscopy Association -IAA-, Holanda). Profesor invitado: Dr. Andre Frank (Francia). Abajo, Dres. David Marshall (Australia) y David Dandy (Reino Unido), anteriores presidentes de la IAA. Dr. Peter Fowler (primer presidente de la International Society of Arthroscopy, Knee Surgery and Orthopaedic Sports Medicine -ISAKOS-, Canadá).

primera y el también holandés Rene Martin de la segunda, se disolvieron para fundar la sociedad 


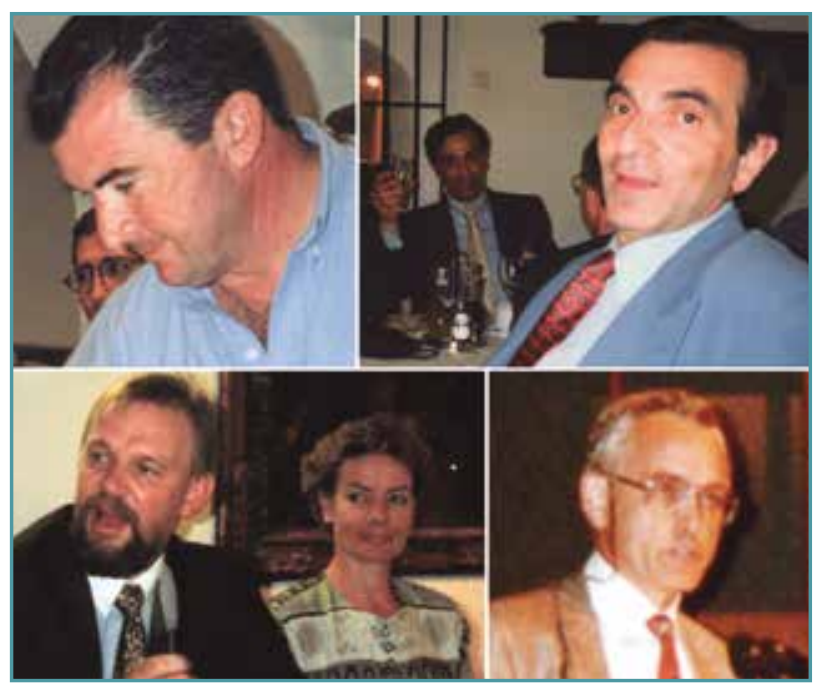

Figura 28. De izda. a dcha., arriba: Dr. Miguel Ángel Martínez Villar (organizador); profesores invitados: Dr. Mike Malek (EE.UU.) y Dr. Pier Paolo Mariani (Italia). Abajo: Dr. L. Panasen (Finlandia) y Dra. T. Werdmark (Suecia), Gary Poehlin (EE. UU.).

conjunta de ambas ISAKOS (International Society of Arthroscopy Knee and Orthopaedic Surgery), de la que fue presidente fundacional el canadiense Peter Fowler.

El XIV congreso se celebró en Cádiz los días 16, 17 y 18 de mayo de 1996. Los organizadores fueron los Dres. Martínez Villar, Suardíaz Espejo, Carrascosa Cerquero y Flores Ruiz. Contó con los siguientes profesores invitados: los estadounidenses Gary Poehling, de Winston-Salem, y Mike Malek, de Washington D.C.; el italiano Pier Paolo Mariani, de Roma; y de los países escandinavos impartieron conferencias el finlandés Panasen y el sueco Werdmark. Paralelamente, se celebró el IV curso de enfermería y el I curso de residentes (Figura 28). Uno de los participantes de ese año, en el que hubo una visita guiada a una finca de toreros y cena con chirigotas, fue el médico alemán Dieter Regier, que hablaba español, y la experiencia fue tan buena que participó en los 6 consecutivos congresos.

El XV congreso se celebró en Valencia los días 16, 17 y 18 de octubre de 1997. Estuvo organizado por José M.a Guinot y Enrique Gastaldi, que por cierto ese año volvió a ser papá, Vicente Reig y R. Colomer. Los invitados fueron los estadounidenses Michael Austin, Lanny Johnson, James Tasto, Freddie Fu -que no pudo asistir y en cuyo lugar

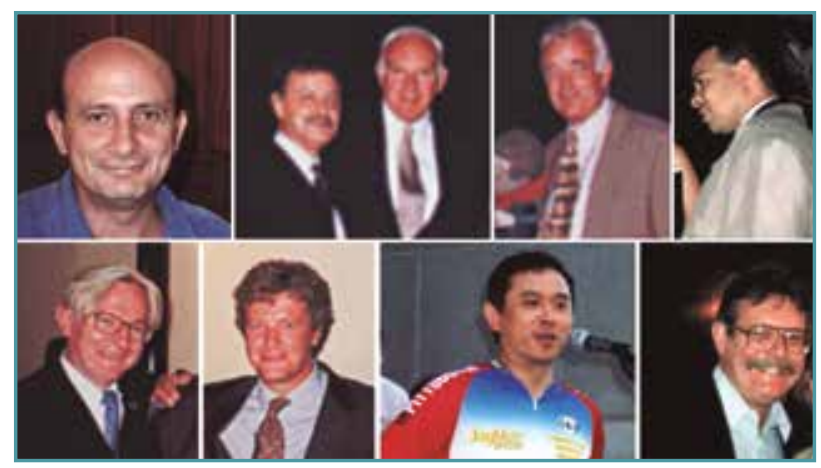

Figura 29. De izda. a dcha., arriba: Dr. Enrique Galindo (nuevo presidente electo), Dr. José M.a Guinot (organizador) y Dr. L. Johnson (EE.UU.); profesores invitados: Dr. J. Tasto (EE.UU.), Dr. Jones (EE. UU.). Abajo: Dr. Henri Coudane (Francia), Dr. Daniel Mole (Francia), Dr. Freddie Fu (EE.UU.) y Dr. M. Austin (EE.UU.).

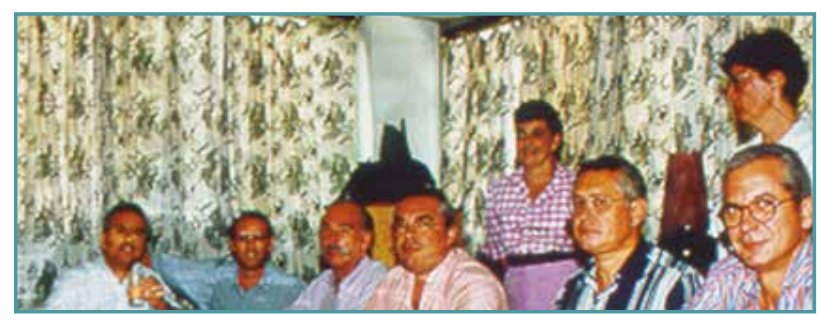

Figura 30. Curso Práctico de Iniciación en Cirugía Artroscópica en los Hospitales de Santa Clara y Sagua La Grande de Cuba, liderado por los Dres. Manolo Baro, Juan José Rey, Ramón Cugat, Ignacio Muñoz, Montse García y Jean Pierre Dubos.

acudió Jones-; y los franceses Henry Coudane, presidente de la Sociedad Francesa de Artroscopia, Daniel Molé y Jean Pierre Dubos. También se celebraron los cursos paralelos de enfermería (V) y de residentes (II). Hubo renovación de presidencia: cesó Juan José Rey y fue elegido Enrique Galindo hasta 1999. Ese año no faltó la falla de la AEA, que evidentemente no se indultó (Figura 29).

También en 1997 la AEA cooperó con el Gobierno de la Comunidad de Canarias en la donación de una torre completa e instrumental, así como en el Curso Práctico de Iniciación en Cirugía Artroscópica. El proyecto se llevó a cabo en los Hospitales de Santa Clara y Sagua La Grande de Cuba. Estuvo liderado por Manolo Baro y participaron el aún presidente Juan José Rey, Ramón Cugat, Ignacio Muñoz, Montse García y Jean Pierre Dubos, miembro de la Sociedad Francesa de Artroscopia, 


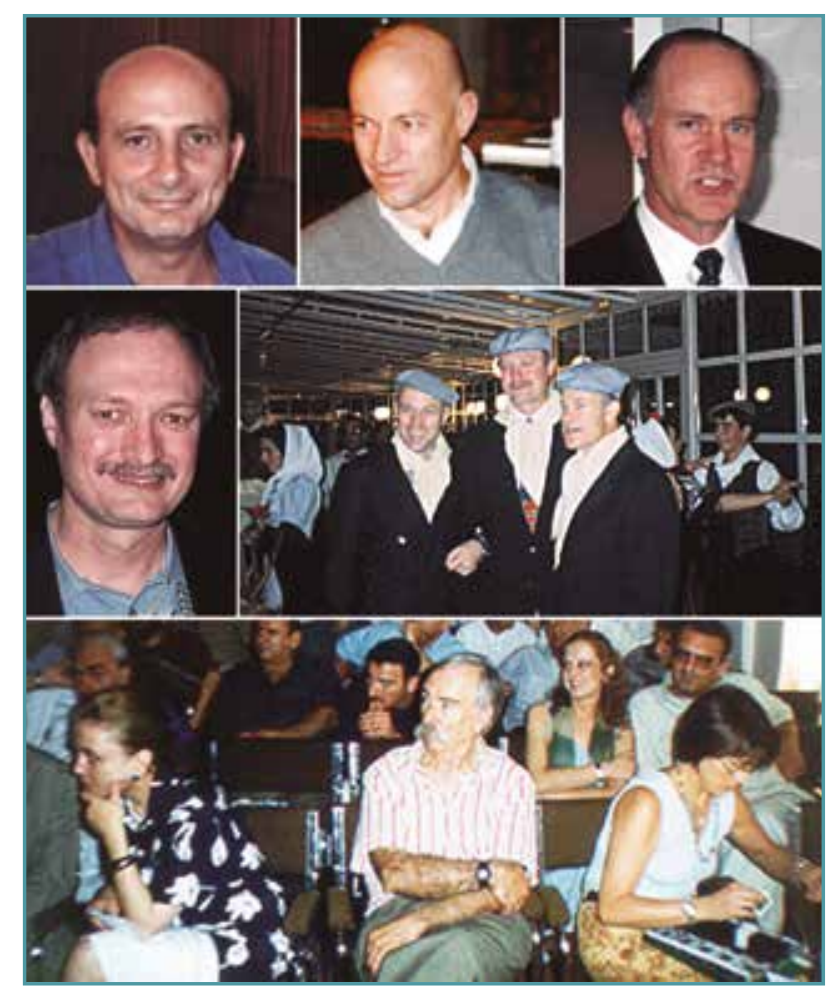

Figura 31. De izda. a dcha., arriba: Dr. Enrique Galindo (organizador); profesores invitados: Dr. Alessandro Castagna (Italia), Dr. Stephen Snyder (EE. UU.). Abajo: Dr. Stephen Burkhart (EE.UU.).

excelente profesor que siempre ha estado muy vinculado a la AEA y del que cabe remarcar como peculiaridad su gran afición por los toros, a la poesía de Federico García Lorca y al género de la zarzuela (Figura 30).

En 1998 se celebró el XVI congreso durante los días 7, 8 y 9 de mayo. Tuvo lugar en Madrid y estuvo organizado por el presidente de la AEA, Enrique Galindo, ayudado por toda la Junta Directiva, Javier Vaquero, José Achalandabaso, Alfonso del Corral, José M.ą Guinot, José M.a Madrigal y Miguel Ángel Martínez Villar. En esa ocasión, la cirugía del hombro fue el "plato fuerte" de las sesiones, de ahí que los invitados fueran los norteamericanos Steven Snyder y Steven Burkhart, acompañados del italiano Alessandro Castagna, de Milán. Una vez más se celebraron los cursos paralelos de enfermería (VI) y de residentes (III). Ese año se celebró "La Verbena", no faltando ni los "chulos" ni las "chulas" al encuentro (Figura 31). También ese año la AEA, en cooperación con la Sociedad Francesa de Artroscopia, impartió durante unos

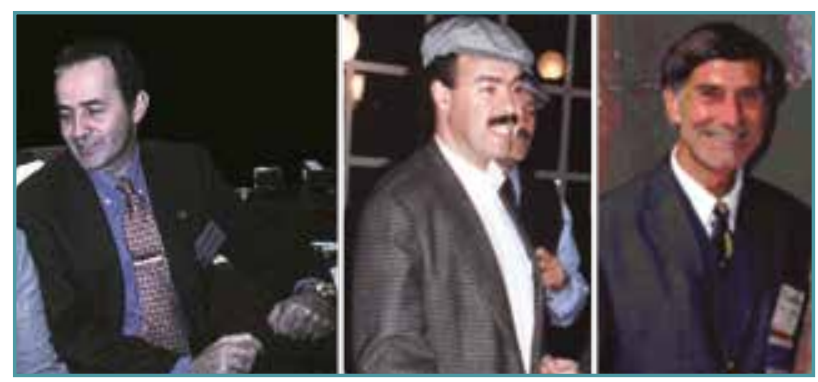

Figura 32. De izda. a dcha., Dr. Javier Vaquero (nuevo presidente electo), Dr. G. Garcés (organizador), $R$. Jakob (Suiza, profesor invitado).

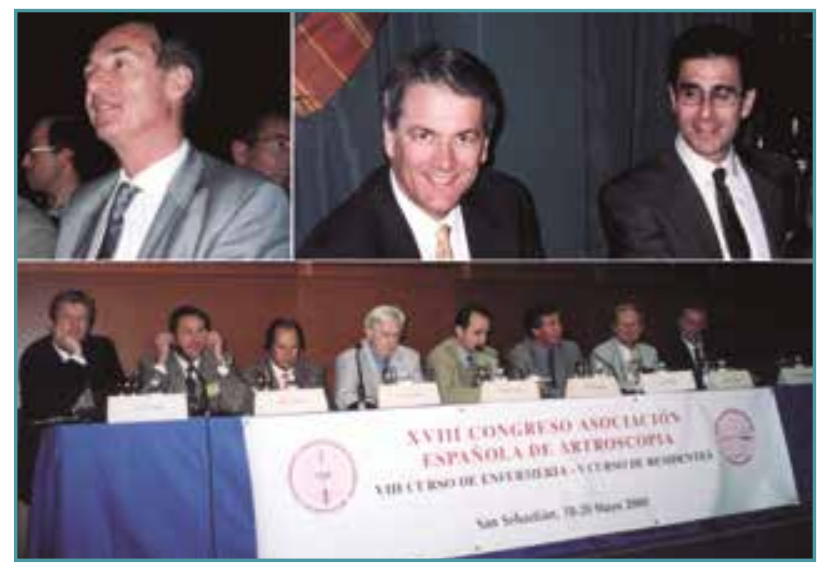

Figura 33. De izda. a dcha., arriba: Dr. José Achalandabaso (organizador); profesores invitados: Dres. Alan Barber y Peter Ferkel. Abajo: Société Française d'Arthroscopie.

días del mes de julio el Education Meeting on Arthroscopy and Knee Surgery en Tbilisi, capital de la República de Georgia.

Al año siguiente, 1999, se celebró el XVII congreso durante los días 6, 7 y 8 de mayo. Tuvo lugar en Las Palmas de Gran Canaria y los organizadores fueron Gerardo Garcés, Juan Nogales y Arnaldo Rodríguez. Los invitados fueron Roland Jakob, de Friburgo, Suiza, y presidente entonces de ISAKOS; Handgody, de Hungría; y Johnson, de los EE.UU. Se volvieron a celebrar los cursos paralelos de enfermería (VII) y de residentes (IV). También hubo renovación de la presidencia, siendo elegido Javier Vaquero hasta 2001. Los participantes de ese congreso, además de recibir educación, vivieron un "Carnaval" muy especial, el de la AEA (Figura 32).

Con el año 2000 se regresó a la Península y el XVIII se celebró en San Sebastián los días 18, 19 y 


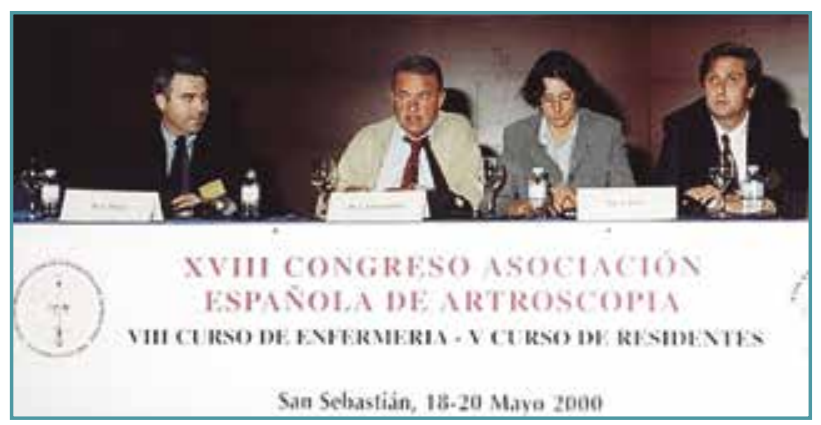

Figura 34. XVIII Congreso de la Asociación Española de Artroscopia.
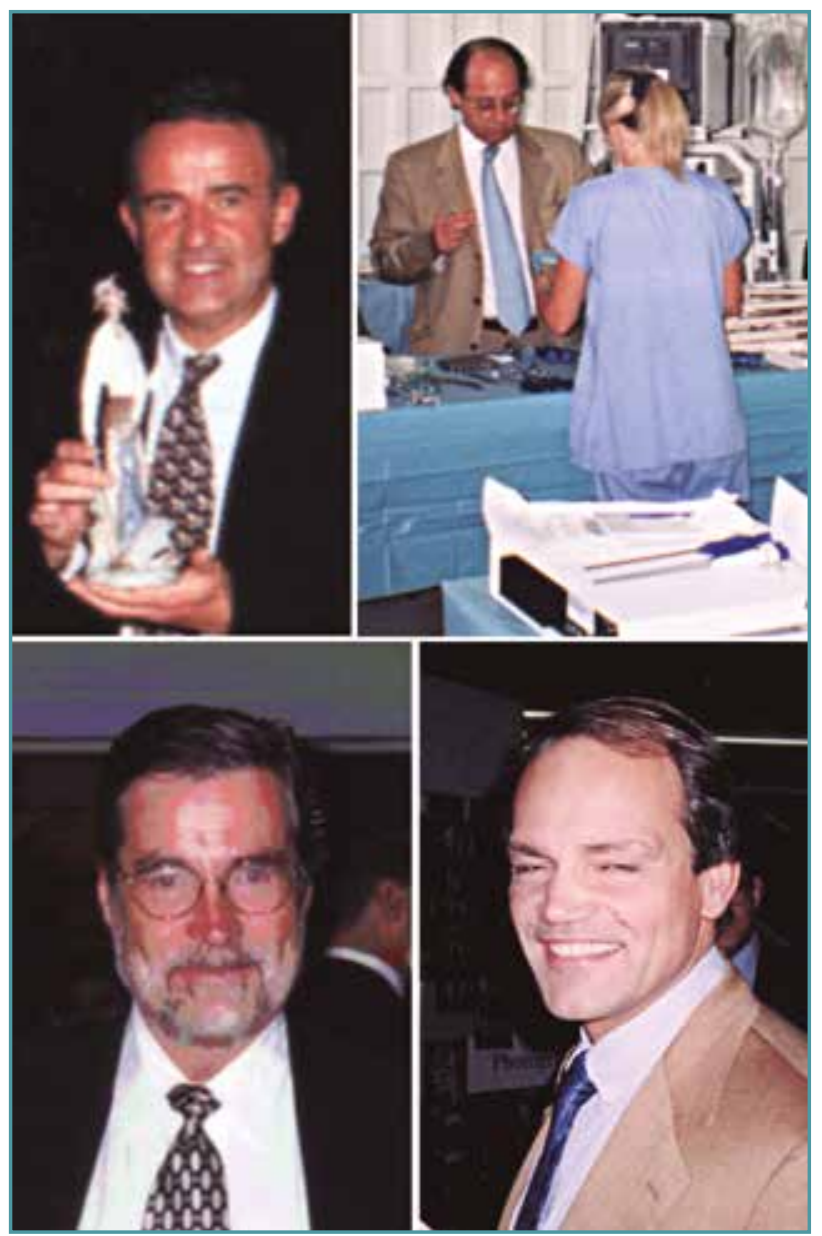

Figura 35. De izda. a dcha., arriba: Dr. José Achalandabaso (nuevo presidente electo); Dr. Cimiano (organizador). Abajo, profesores invitados: Dr. Don Johnson (EE.UU.) y Dr. J. P. Benedetto (Austria).

20 de mayo. Los organizadores fueron José Achalandabaso, Eduardo Escobar y Pedro Blanco. En esta ocasión, hubo una participación especial de la Sociedad Francesa de Artroscopia, por lo que los profesores invitados fueron representantes de la entidad mencionada: Thierry Boyer, Henry Coudane, Jean François Kempf, Jacques Philippe Laboureau, David Molé, Jean Pierre Dubos, Henri Dorfmann y los estadounidenses Alan Barber y Richard Ferkel. Una vez más se celebraron los cursos paralelos de enfermería (VIII) y de residentes (V) (Figuras 33 y 34). Durante el año 2000 apareció un nuevo Laboratorio de Anatomía para realizar cursos de aprendizaje con especímenes cadavéricos. Se halla en la Universidad Complutense de Madrid.

Al año siguiente, 2001, se celebró el XIX congreso en Santander los días 10, 11 y 12 de mayo. Los organizadores fueron Gómez Cimiano y Cimadevila Isla. También se celebraron los cursos paralelos de enfermería (IX) y de residentes (VI). Los profesores invitados fueron Karl Peter Benedetto, de Austria, y presidente de la ESSKA; Vladimir Bovic, del Reino Unido; Olivier Gagey, de Francia; Riccardo Minola, de Italia; Hans Stäubli, de Suiza; René Verdonk, de Bélgica y Donald Johnson, de Los EE. UU. Volvió a renovarse la presidencia y fue elegido José Achalandabaso hasta 2003 (Figura 35).

Al año siguiente, 2002, el XX congreso se celebró en Salamanca los días 9, 10 y 11 de mayo. Una vez más, se celebraron los cursos de enfermería (X) y de residentes (VII) y la I Jornada de Fisioterapia y Artroscopia. Los organizadores fueron Pérez-Caballer, de Pedro Moro y Sánchez Sotelo. Los ponentes invitados fueron Alessandro Castagna, de Italia; Alejandro Badía, de los EE.UU.; Laszlo Hangody, de Hungría; y 3 estadounidenses: Peter Kurzweil, Mike Malek y Felix Savoie III. El Aula Magna, el Aula de Fray Luis de León y el Ayuntamiento se abrieron para agasajar a la AEA y reconocer a algunos de sus miembros como Hijos Predilectos de la cuna del saber hispano.

El año siguiente, 2003, el XXI congreso se celebró en Zaragoza los días 15, 16 y 17 de mayo. Los organizadores fueron Calvo Díaz, Benedí Alcaine y Domingo Cebollada. También se celebraron los cursos de enfermería (XI), de residentes (VIII) y el I Curso de Fisioterapia. Los profesores invitados fueron Guillermo Arce, de Argentina; Matts Brittberg, de Suecia; de los EE. UU., Buford, Burkhart y Vargas; de Brasil, Cohen; de Noruega, Kaltenborn; Mariani de Italia, Orizola de Chile y Valero de Mé- 


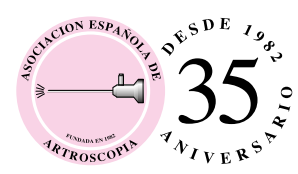

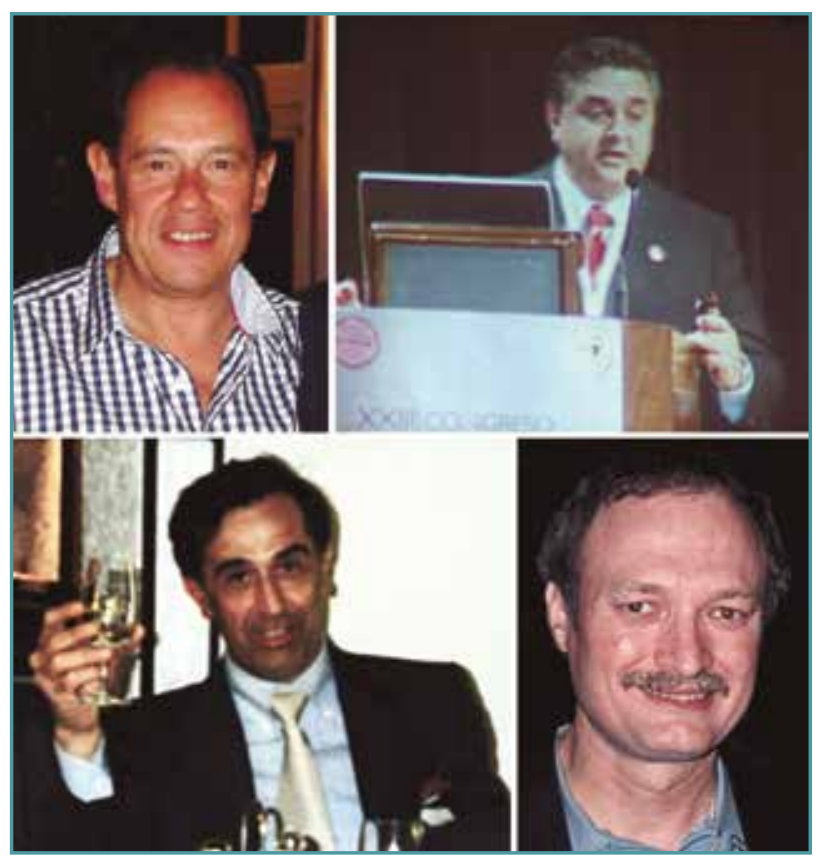

Figura 36. De izda. a dcha., arriba: Dr. Antonio Estévez (presidente electo 2003-2005). Profesores invitados: Dr. M. Cohen. Abajo: Dr. P. P. Mariani y Dr. S. Bukhart (EE. UU.).

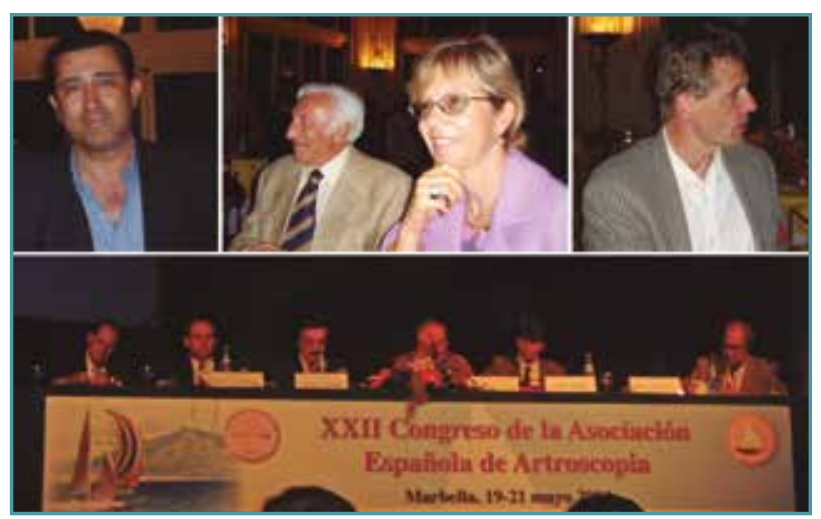

Figura 37. De izda. a dcha. arriba: Dr. Manuel Díaz Samada (organizador). Profesores invitados: Dr. G. CeruIli, Dr. P.H. Hardy, Dr. J.C. Leitao, Dr. Van Dijck.

xico. Hubo cambio de presidencia y fue elegido Antonio Estévez hasta 2005 (Figura 36).

En 2004, la sede del XXII congreso volvió a Marbella, Málaga, durante los días 19, 20 y 21 de mayo. El organizador fue Manuel Díaz Samada. Se celebraron también los cursos de enfermería (XII) y de residentes (IX). Los invitados, entre otros, fueron Cerulli, de Asís, Italia; Hardy, de Francia; Leitao, de Portugal; y van Dijk, de Holanda (Figura 37).

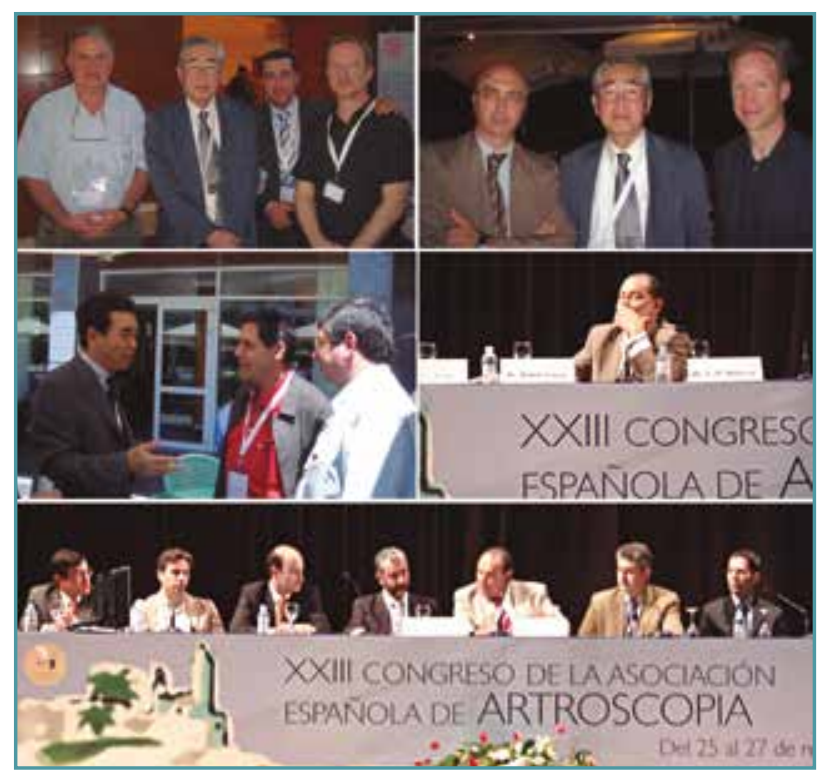

Figura 38. XXIII Congreso de la Asociación Española de Artroscopia.

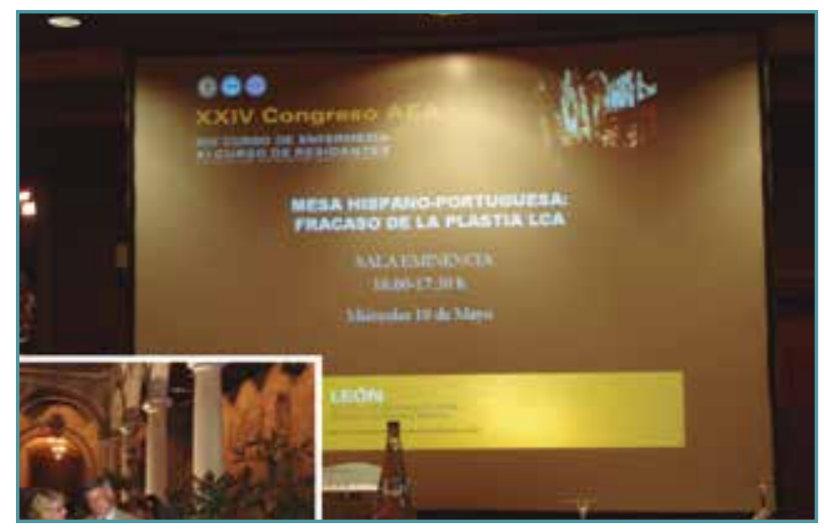

Figura 39. XXIV Congreso de la Asociación Española de Artroscopia.

En el año 2005 se celebró el XXIII congreso durante los días 25, 26 y 27 de mayo. La sede fue Sitges, Barcelona, y los organizadores fueron Sergi Massanet, Juan Carlos Monllau García, Eva Estany, Vilaró y Xavier Juan Segarra. También se celebraron los cursos de enfermería (XIII) y de residentes (X). En esa ocasión, hubo intercomunicación con la comunidad artroscópica asiática y con la ESSKA. Los profesores invitados fueron Hiroshi Ikeuchi, Mitsuo Ochi e Inoue, de Japón; Kelberine y Lafosse, de Francia; Kohn, Ergelett y Fritchy, de Alemania; Denti, de Italia; Thomas, del Reino Unido; Abhrams y Romeo, de los EE. UU.; van Arkel, de 

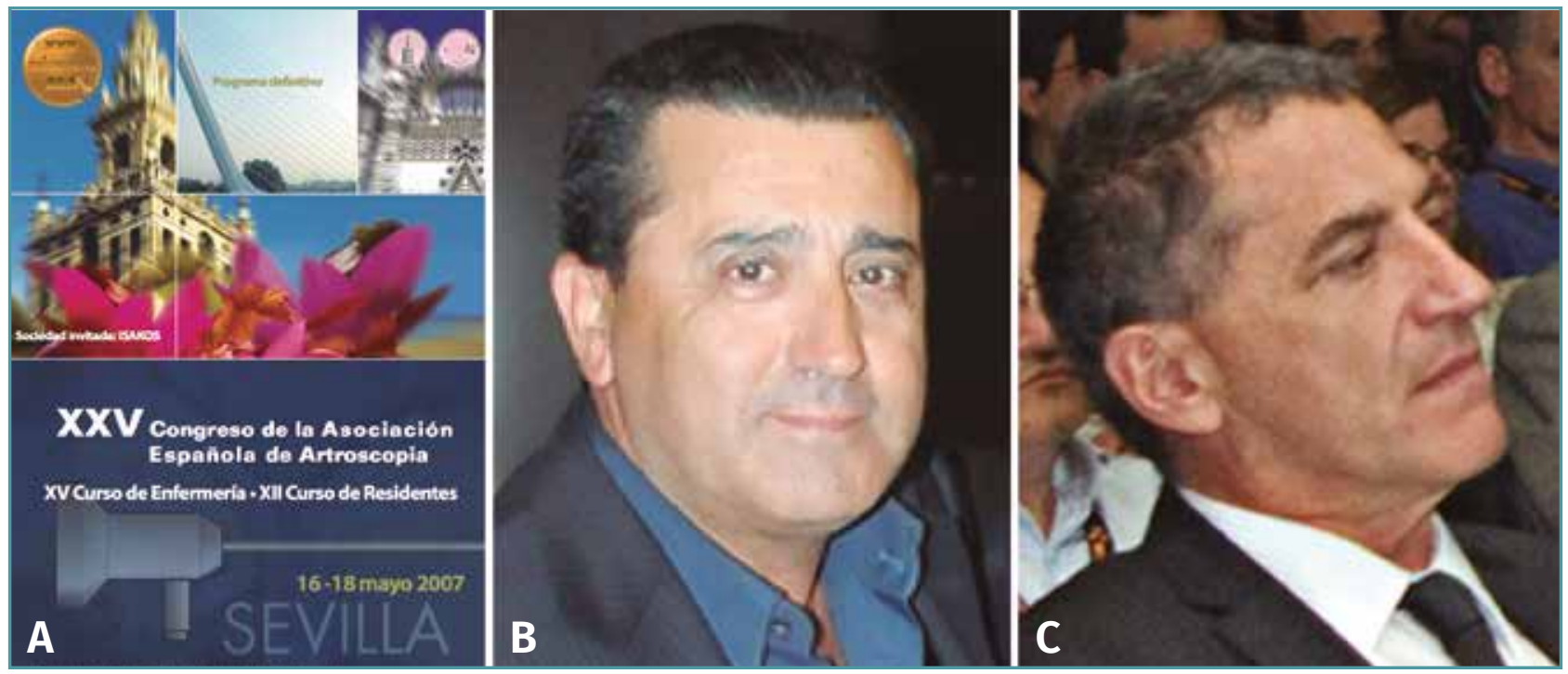

Figura 40. A: XXV Congreso de la Asociación Española de Artroscopia. B: Dr. Manuel Díaz Samada. C: Dr. Laurent Lafosse.

Los Países Bajos; y René Verdonk, de Bélgica. El nuevo presidente electo fue Manuel Díaz Samada hasta 2007 (Figura 38).

El XXIV congreso se celebró en León el año 2006. Los organizadores fueron Galán Gallego, Ramos Guallar y Amigo Fernández. Una vez más se celebraron los cursos de enfermería (XIV) y de residentes $(\mathrm{XI})$. Los ponentes invitados fueron: de Portugal, Espregueira; de Francia, Flurin y Lafosse; de México, Paulovic; de Italia, Porcellini y Taverna; y de los EE. UU., Kevin Stone (Figura 39).

En 2007 se celebró en Sevilla el XXV Congreso de nuestra asociación (Figura 40A), conjuntamente con el XV Curso de Enfermería y el XII Curso de Residentes, con la presidencia del Dr. Díaz Samada (Figura 40B). El comité organizador lo dirigía el Dr. José M.a Madrigal, junto con los Dres. Rafael Muela, Carlos Molano, Gonzalo de la Cuesta, Emilio López Vidriero y José E. Minguet. Fueron invitados los Dres. Laurent Lafosse, de Francia (Figura 40C); Alessandro Castagna, de Italia; Ofer Levy, de Gran Bretaña; Felipe Cámara y José David González
Bernal, de México; Mitsuo Ochi, de Japón; Freddie Fu, Carlos Guanche, Stephen Snyder, Lonnie Paulos y Bertram Zarins, de los EE. UU. Los Dres. Lafosse, Snyder, Castagna y Zarins nos ofrecieron clases magistrales sobre la patología de hombro, haciendo lo propio el Dr. Carlos Guanche sobre artroscopia de cadera, que despegaba en nuestro país como un cohete (incluso se planteaba en este curso si representaba una moda) (Figura 41A).

Los profesores Levy y Castagna, junto con los Dres. Enrique Galindo y Pau Golanó, nos enseña-

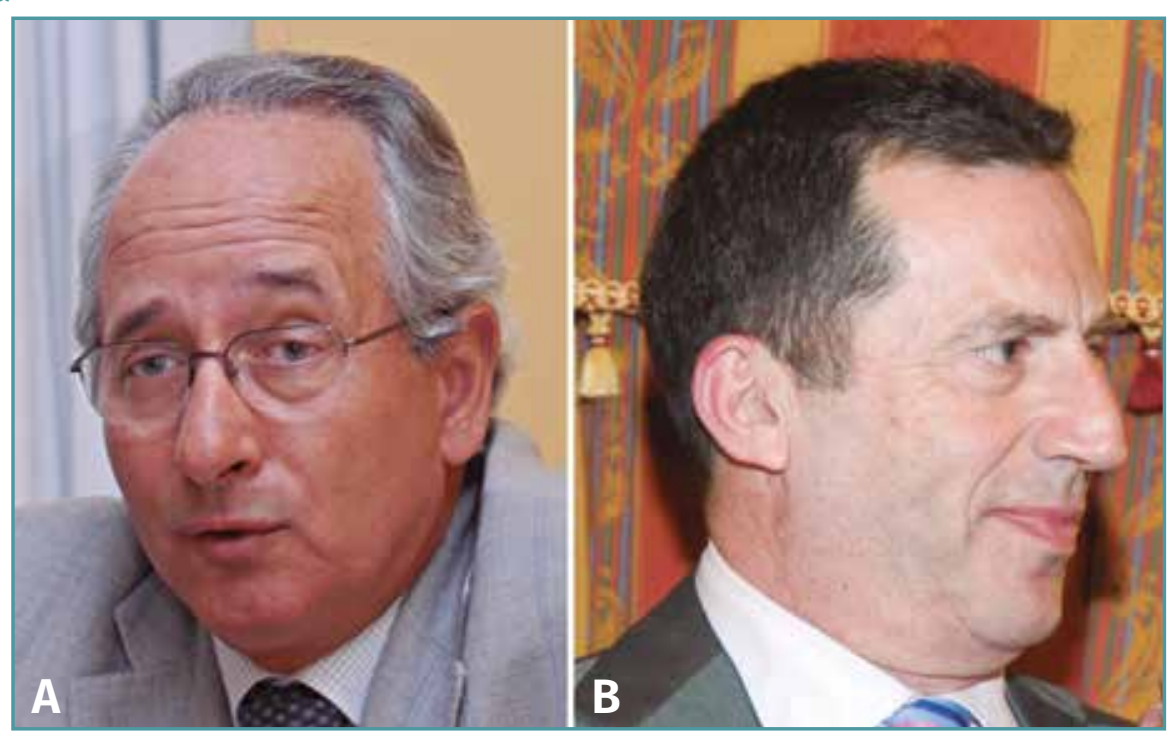

Figura 41. A: Dr. José M.ạ Madrigal. B: Dr. José M.ạ Altisench. 


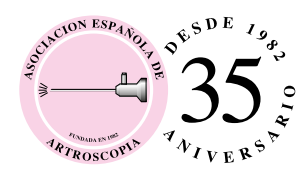

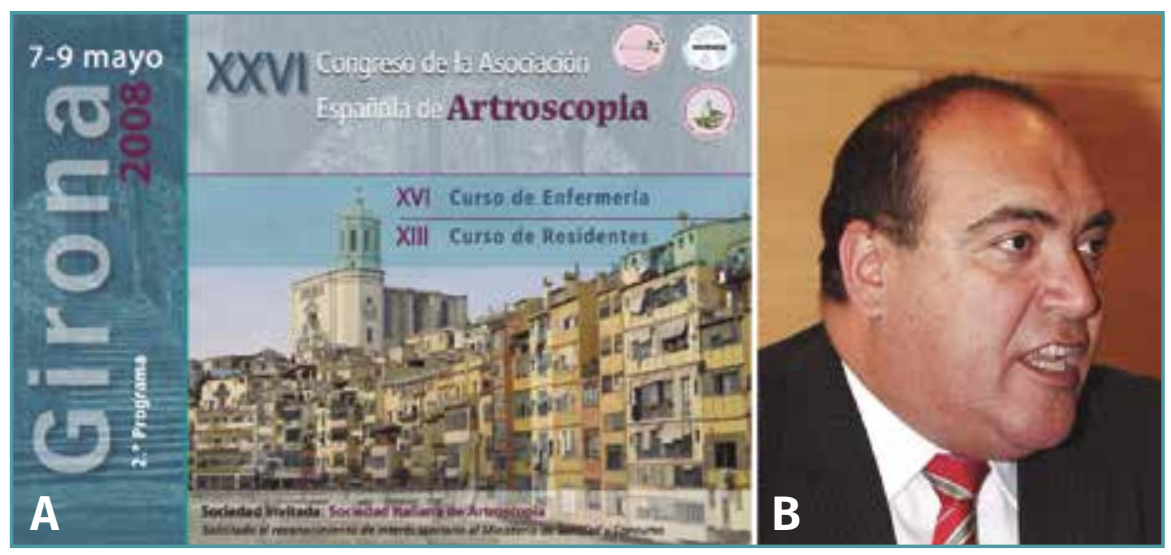

Figura 42. A: XXVI Congreso de la Asociación Española de Artroscopia. B: Dr. José M. a Centenera.

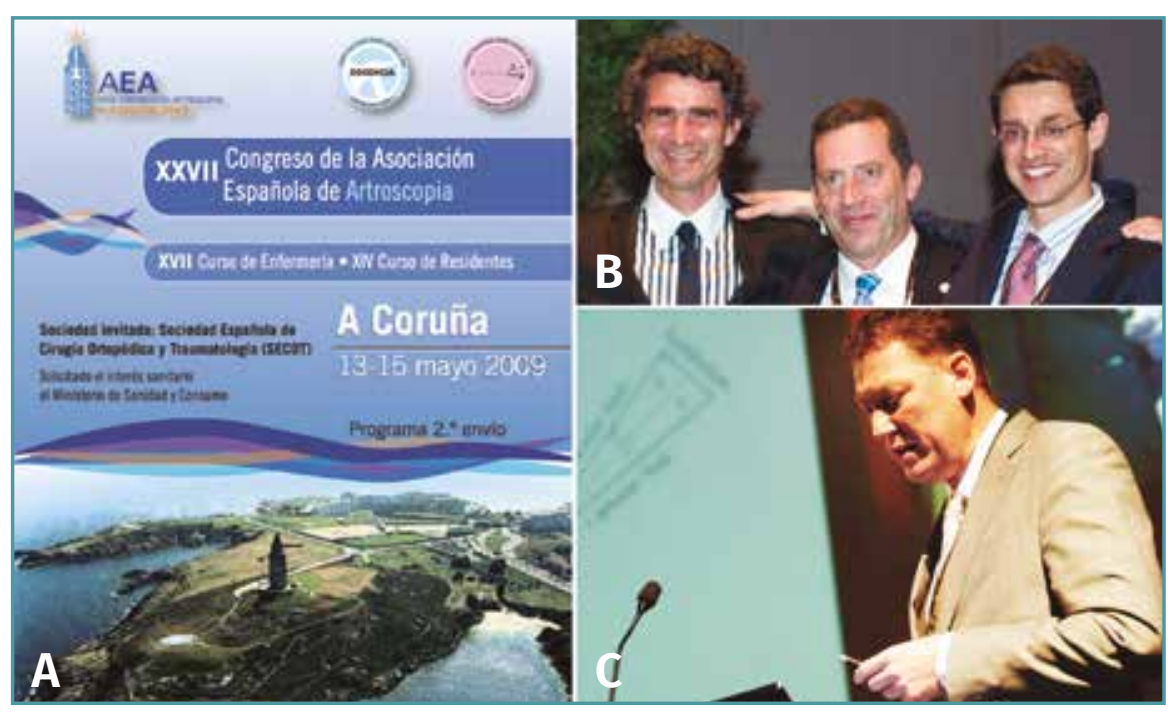

Figura 43. A: XXVII Congreso de la Asociación Española de Artroscopia. B: Dres. Dejour, Altisench y Rafael Arriaza. C: Dr. Labs.

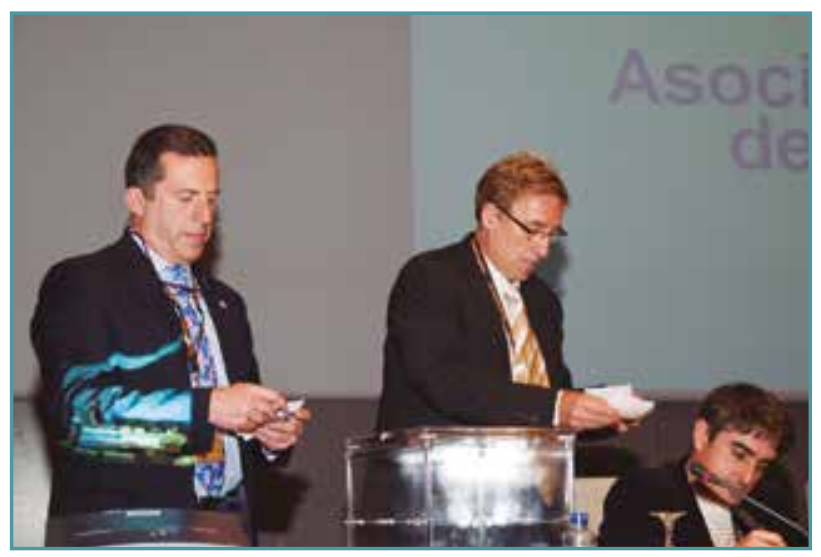

Figura 44. Dres. Altisench, Massanet y Ricardo Crespo. ron de forma práctica diferentes aspectos del hombro. El Dr. Freddie Fu nos explicó de primera mano la importancia de la reconstrucción del ligamento cruzado anterior de una forma anatómica, en especial con el doble fascículo. El futuro aparecía con la cirugía navegada y robótica con el Dr. Levy y con las terapias celulares de mano del Dr. Mitsuo Ochi, en sendas conferencias. En este congreso asume la presidencia José M. a Altisench para el periodo 2007-2009 (Figura 41B).

El XXVI Congreso de la AEA se realizó en Girona (Figura 42A), con la presidencia de José M.a Altisench y estando el Comité Organizador compuesto por José M.a Centenera (Figura 42B), Marc Tey, Ramón Roig, Santiago Albors, José Luis Bada, Jesús Marimón y Salvador Geli. La Sociedad Italiana de Artroscopia fue la invitada este 2008. Lafosse, Taverna, Porcellini y Campi nos volvieron a demostrar su habilidad quirúrgica en cirugía artroscópica de hombro, mientras que se realizaron interesantes discusiones sobre artroscopia de cadera con especialistas de renombre mundial, como los Dres. Richard Villar de Gran Bretaña, Michael Dienst de Alemania o Thomas Sampson de los EE.UU., todos ellos padres de la International Society of Hip Arthroscopy, creada en 2008. Sobre la cirugía de ligamento cruzado anterior, pudimos asistir a las discusiones de los Dres. Minola, Cerulli, van der Hart, Allard y Unwin.

En 2009 se realiza en A Coruña el XXVII Congreso de la AEA (Figura 43A), con la organización por parte de los Dres. Rafael Arriaza, Gonzalo Couceiro, Jesús Aizpurúa, Alejandro Prego, Pablo Codesido, J. César Fernández y Santiago Gómez 


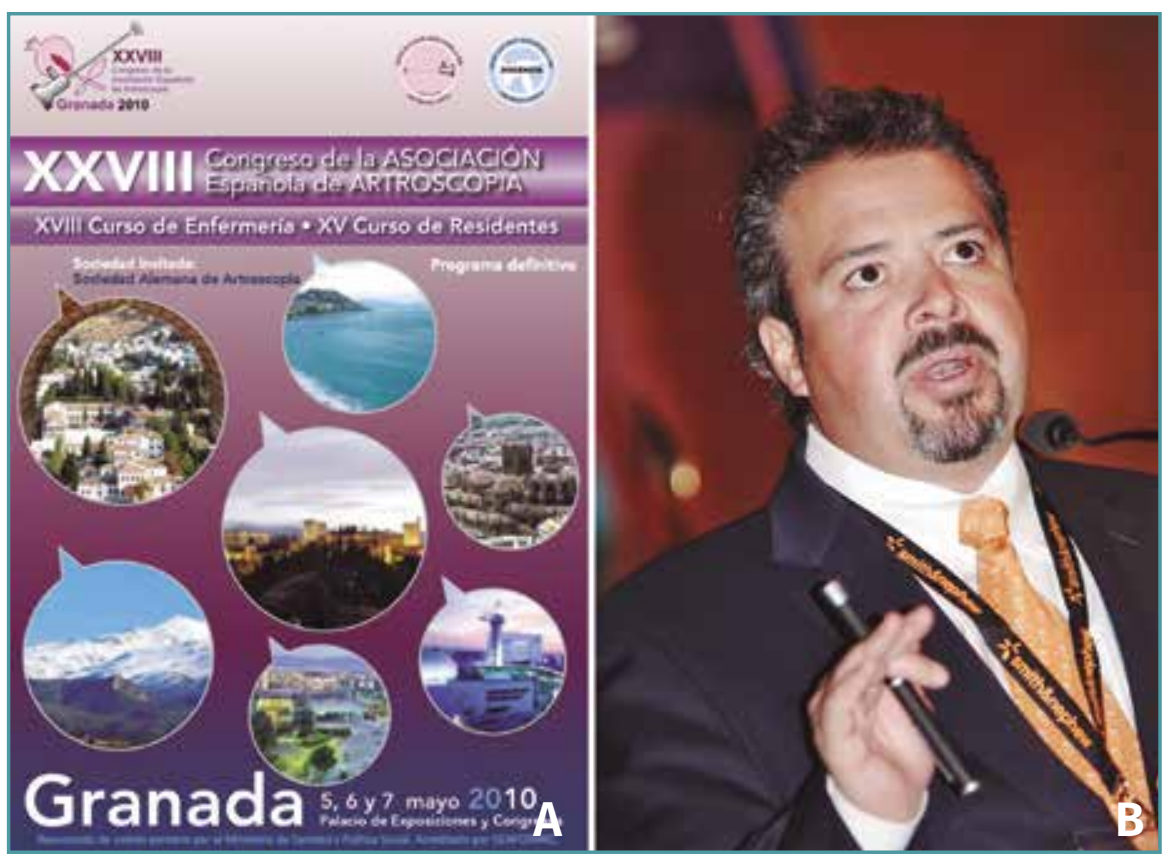

Figura 45. A: XXVIII Congreso de la Asociación Española de Artroscopia. B: Dr. Víctor Ilizaliturri.

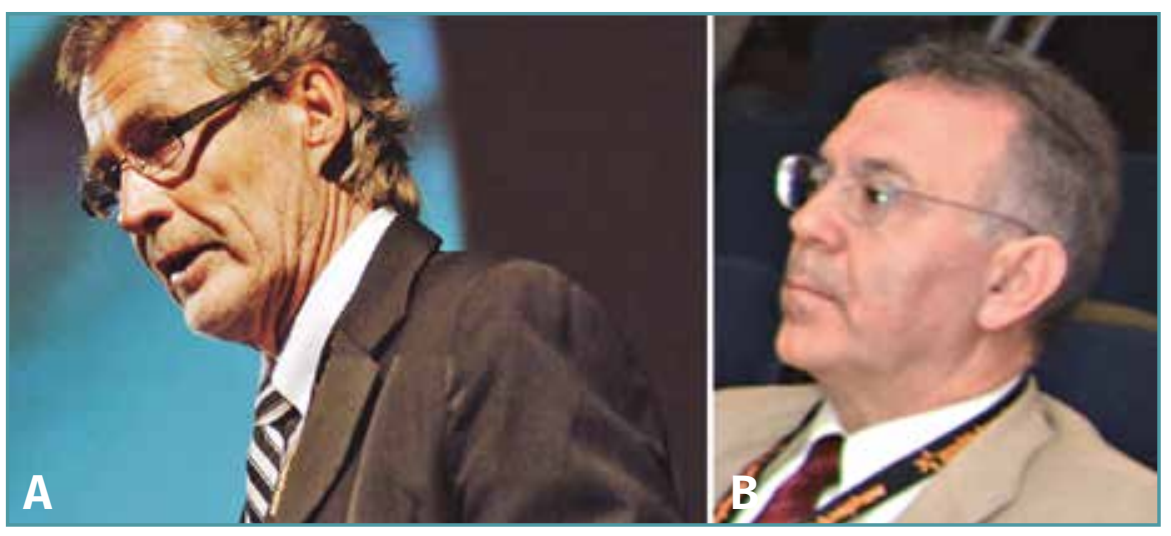

Figura 46. A: Dr. Don Johnson. B: Dr. Manuel Zabala.

(Figura 43B). La sociedad invitada fue la Sociedad Española de Cirugía y Traumatología. Una mesa redonda sobre temas profesionales con un gran éxito de asistencia nos mostró la difícil relación de nuestra profesión con la economía. Sobre el ligamento cruzado nos hablaron Hans Passler de Alemania y Espregueira-Mendes de Portugal. Wolf y Mehalik, de los EE. UU., nos hablaron de patología de hombro; Labs, de Alemania, y Villar, de Gran Bretaña, nos hablaron de cadera; mientras que nos mostraron diferentes alternativas quirúrgicas los Dres. Paribelli de Ita- lia, Tennent de Gran Bretaña, Castellanos de México, Dejour de Francia, van Dijk de Holanda y Yáñez de Chile (Figura 43C). En este congreso fue elegido Sergi Massanet como presidente para el periodo 2009-2011 (Figura 44).

Granada fue el escenario del XXVIII Congreso de la AEA, en 2010, con la presidencia del Comité Organizador por parte del Dr. Manuel Zabala (Figura 45A). La sociedad invitada para este congreso fue la Sociedad Alemana de Artroscopia. Como profesores invitados extranjeros, acudieron Víctor Ilizaliturri desde México (Figura 45B) y Boyer de Francia, con gran conocimiento del manejo de la artroscopia de cadera; Nebelung desde Alemania, Randle de Canadá y Costa de Portugal nos ofrecieron sus charlas de hombro; Don Johnson desde Canadá, Labs y Paessler desde Alemania, Djian desde Francia y Ramírez de México nos ofrecieron toda su experiencia en rodilla; Dalemans y Vanlauwe de Bélgica y Zaffagnini de Italia nos explicaron los avances en celularidad. Mención especial tuvo la visita nocturna organizada a una maravilla mundial como la Alhambra por parte de los asistentes al congreso (Figura 46).

En 2011, viajamos hasta Santa Cruz de Tenerife para celebrar el XXIX congreso, con la Arthroscopy Association of North America (AANA) como sociedad invitada (Figura 47A). El Comité de Organización fue presidido por el Dr. José Luis Pais Brito. Como profesores invitados, Fidel Dobarganes desde México nos habló de ligamentos, Thomas J. Gill desde los EE. UU. nos habló de menisco, R. Verdonk de Bélgica sobre injertos 


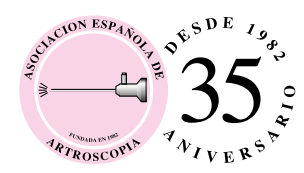

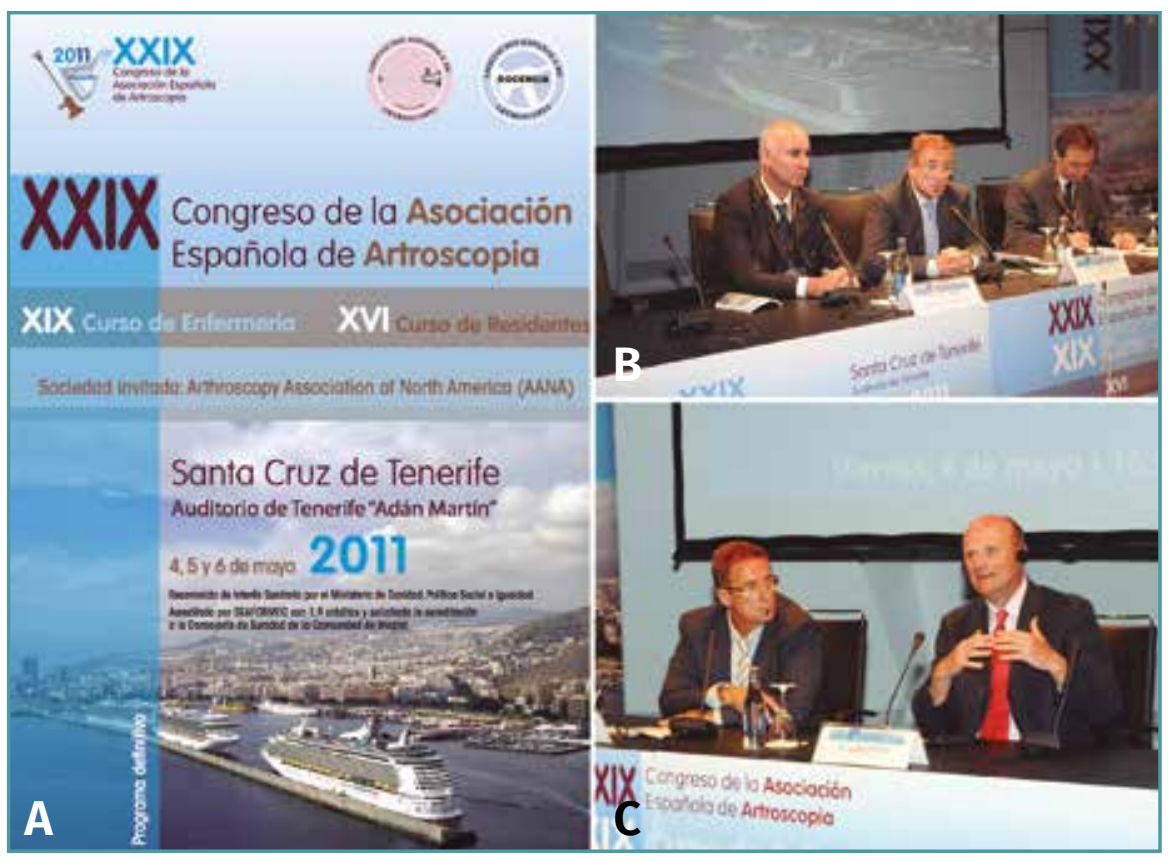

Figura 47. A: XXIX Congreso de la Asociación Española de Artroscopia. B: Dres. Pais, Massanet y Monllau. C: Dres. Massanet y Damian Griffin.

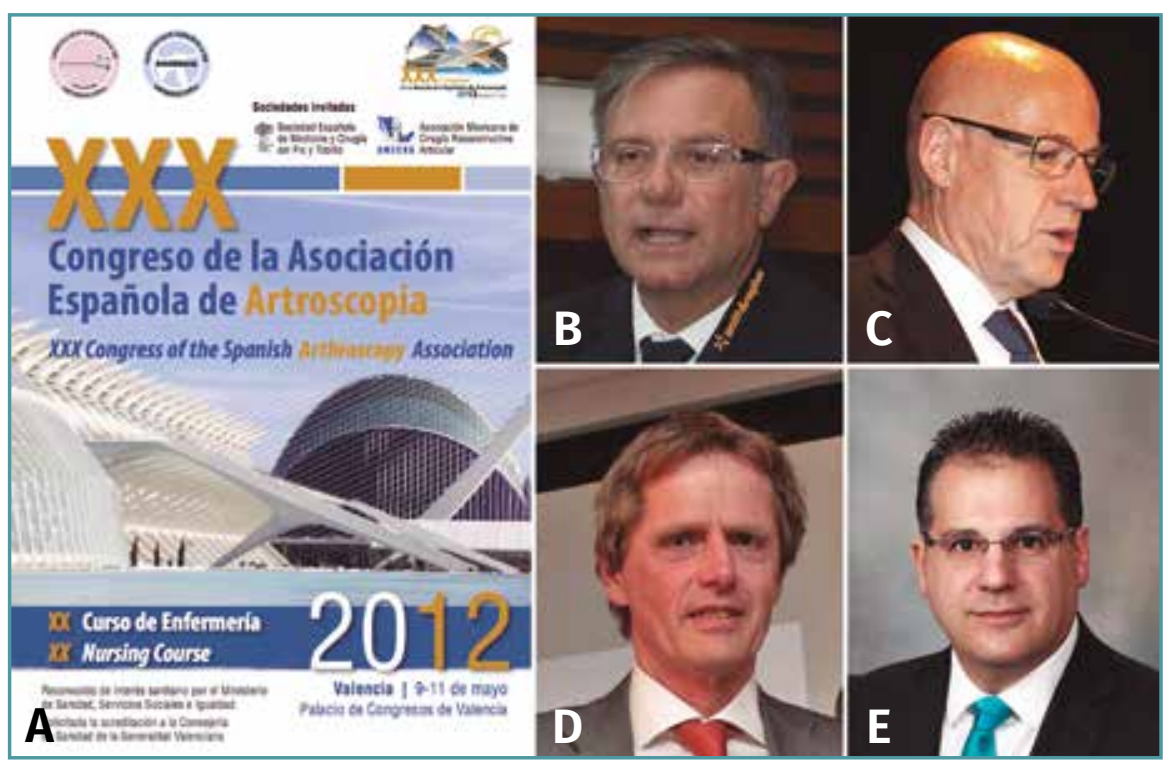

Figura 48. A: XXX Congreso de la Asociación Española de Artroscopia. B: Dr. Eduardo Sánchez Alepuz. C: Dr. Alex Castagna. D: Dr. C. Niek van Dijk. E: Dr. Joaquín Sánchez Sotelo.

artificiales, Luis Guillermo Ibarra de México habló de rodilla, Laszlo Hangody de Hungría realizó una clase magistral de cartílago, Damian Griffin desde Reino Unido nos enseñó varios temas en cadera, J. Clemente Ibarra de México habló so- bre hombro, como Bruno Toussaint de Francia, Paolo Avanza de Italia y Thomas Deberardino de los EE. UU. (Figura 47 B y C). En este congreso cesa como presidente de la asociación el Dr. Sergi Massanet y asume su cargo el Dr. Joan Carles Monllau García por el periodo 2011-2013.

La edición XXX del congreso de nuestra asociación se celebró en Valencia (Figura 48A) bajo la presidencia del Comité Organizador Local del Dr. Eduardo Sánchez Alepuz (Figura 48B). Las sociedades invitadas fueron la Sociedad Española de Medicina y Cirugía del Pie y Tobillo y la Asociación Mexicana de Cirugía Reconstructiva Articular. Como profesores invitados, asistieron el Dr. Alejandro Badia de los EE.UU. dándonos lecciones en muñeca, el Dr. Claudio Mella de Chile en cadera, Fidel Dobarganes de México nos volvió a hablar de hombro, como Félix H. Savoie de los EE. UU. y Alex Castagna de Italia (Figura 48C). Héctor M. Arredondo de México y John W. Xerogeanes de los EE.UU. nos hablaron de rodilla, Nick van Dijk de Holanda de tobillo (Figura 48D) y Joaquín Sánchez Sotelo (Figura 48E) desde los EE.UU. nos aclaró diversos aspectos sobre la investigación en artroscopia, además de su dominio del codo. Estos últimos años fueron sin duda muy duros en el ámbito económico y social. En gran parte de los países occidentales, y en especial en el nuestro, se instauró una profunda crisis económica y social a la cual no fuimos ajenos. Una de las consecuencias que observamos fue la difi- 


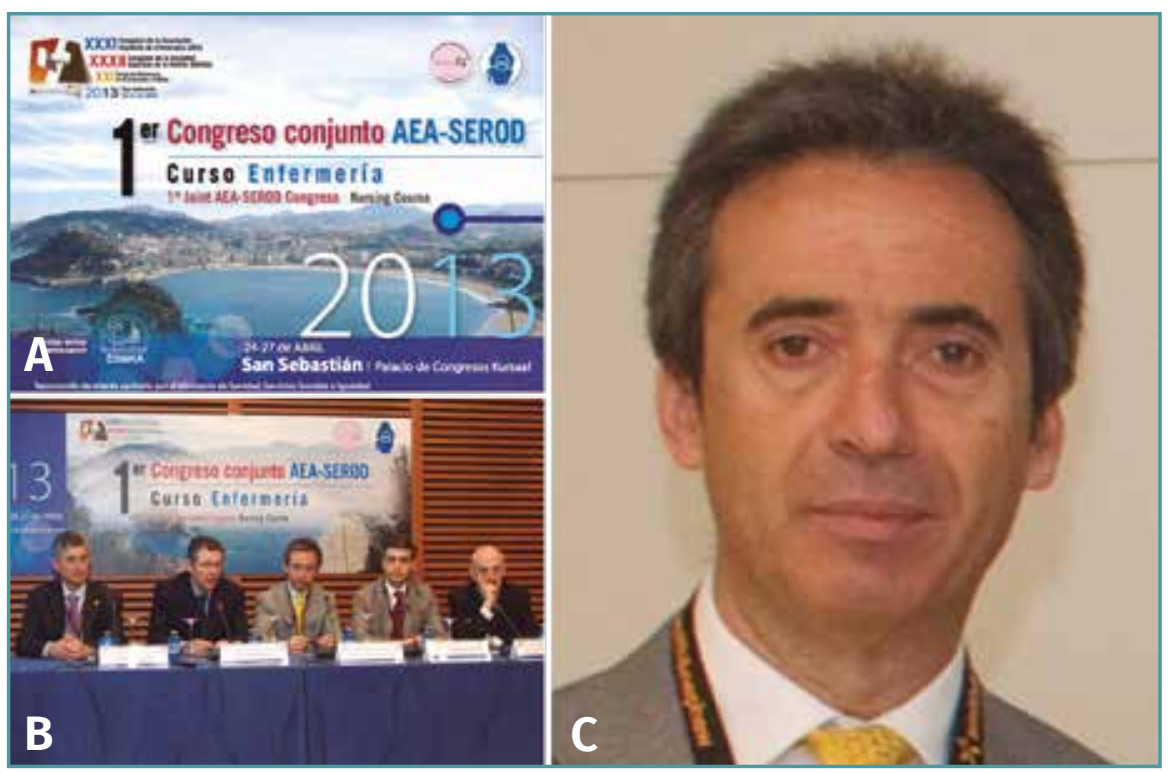

Figura 49. A: I Congreso Conjunto AEA-SEROD. B: Dres. Cuéllar, Maestro, Monllau, Espreguiera y Valentí. C: Dr. Joan Carles Monllau García.

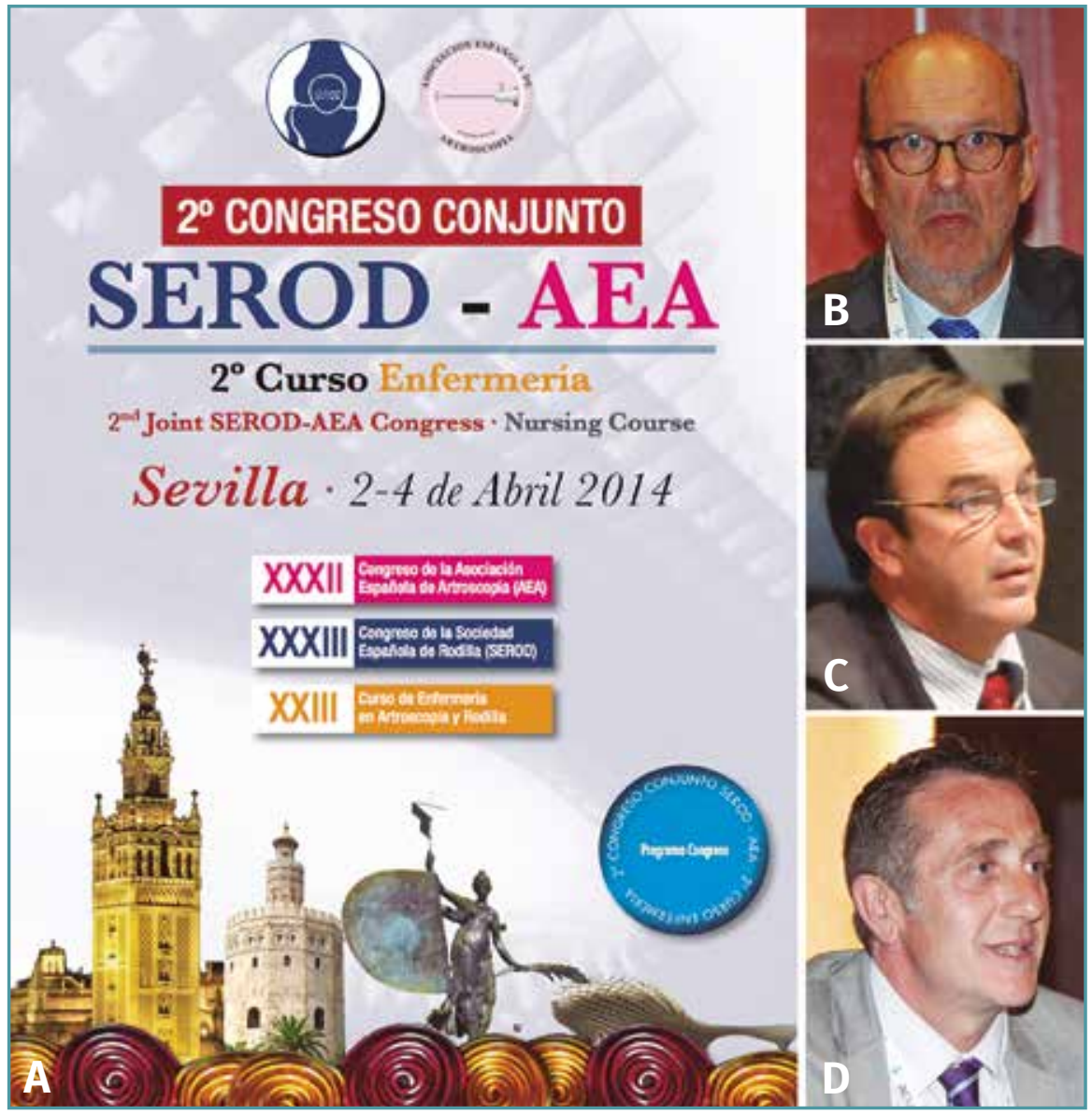

Figura 50. A: Il Congreso Conjunto SEROD-AEA. B: Dr. Rafael Muela. C: Dr. Rafael Canosa. D: Dr. Ángel Calvo. cultad por parte de muchos de los participantes para acudir a su cita anual con el congreso, limitándose no solo en el número de días, sino también reduciendo el número de participantes y acotando los gastos que toda reunión de este tipo comporta. Las casas comerciales tampoco fueron ajenas a estos problemas, debiendo reducir e incluso renunciando a la cita en muchos de los eventos de esta y otras sociedades. Por estos y demás motivos, se acordó que a partir de 2013 el Congreso anual de la AEA y la SEROD se realizara de forma conjunta, para poder reducir una gran parte del gasto tanto para los organizadores como para los asistentes. Dichas sociedades presentaban muchos puntos en común y, por ello, en las respectivas asambleas se apoyó dicha iniciativa por la mayoría de sus miembros. Se acordó también que la organización correría a cargo de ambas sociedades de forma alternativa, respetando en primer turno a la AEA, que había seleccionado su sede en San Sebastián, y se aceptaba la celebración del siguiente congreso en la sede escogida por la SEROD, en Sevilla.

De este modo llegamos a 2013, con la realización del I Congreso Conjunto AEA-SEROD, en San Sebastián, siendo por tanto el XXXI Congreso de la AEA y el XXXII de la SEROD (Figura 49 A y B). Este año la sociedad invitada fue la ESSKA. El presidente del Comité Organizador fue el Dr. 


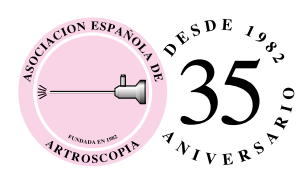

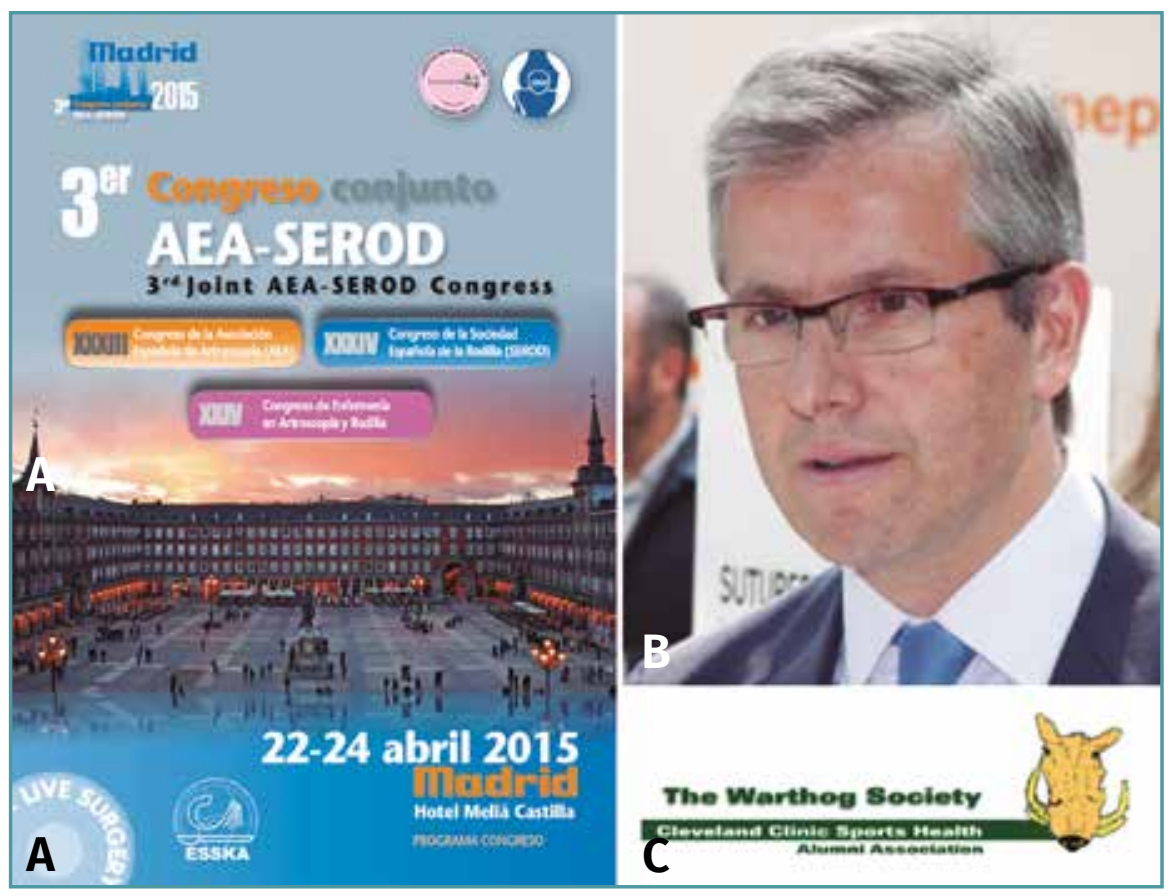

Figura 51. A: III Congreso Conjunto AEA-SEROD. B: Dr. Manuel Leyes. C: The Warthog Society.
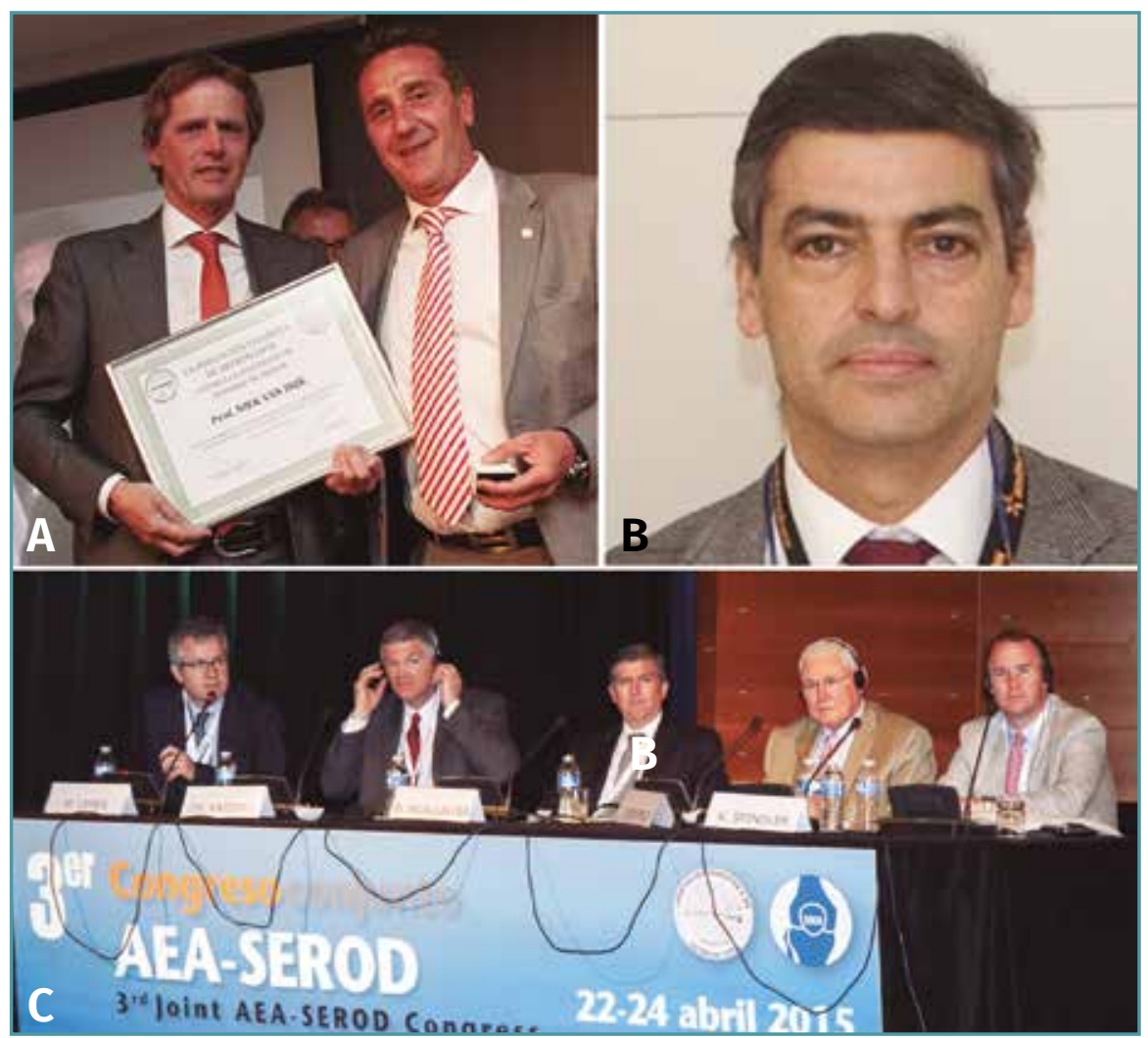

Figura 52. A: Dr. Nick van Dijk (izda.) y Dr. Ángel Calvo (dcha.). B: Dr. Espregueira-Mendes. C: Dr. John Bergfeld, segundo por la dcha.
Ricardo Cuéllar y contó con la colaboración del Dr. Juan Ramón Valentí como coordinador AEA/SEROD. Para este primer congreso conjunto fueron invitados 30 profesores extranjeros, entre los que destacaron Becker, Benazzo, Espregueira, Lafosse, Restrepo, Sánchez Sotelo, Verdonk o Villar. Además, en este congreso cesó en su cargo el Dr. Joan Carles Monllau García (Figura 49C), que fue asumido por el Dr. Rafael Canosa para el periodo 2013-2015.

El II Congreso Conjunto AEA-SEROD se celebró en Sevilla en 2014 (Figura 50A), siendo presidente del Comité Organizador el Dr. Rafael Muela (Figura 50B) con la colaboración del Dr. Juan Ramón Valentí como coordinador AEA-SEROD. Se invitó a dos mesas de ponencias a la Sociedad de Traumatología Deportiva (SETRADE) y a la ESSKA. Un total de 23 ponentes invitados extranjeros y 155 ponentes nacionales impulsaron un congreso de alto nivel, pero marcado por un evento luctuoso. El presidente en activo, Dr. Rafael Canosa, fallecía el 1 de febrero de 2014 (Figura 50C). De forma automática, el vicepresidente, Dr. Ángel Calvo, se hizo cargo de la presidencia, para poder seguir gestionando la asociación (Figura 50D). Por ello, y como situación excepcional, se desarrolló en este congreso una elección anticipada de vicepresidente, en la cual se eligió al Dr. Ricardo Cuéllar. Nuestra revista Cuadernos de Artroscopia cambia de denominación para adoptar 


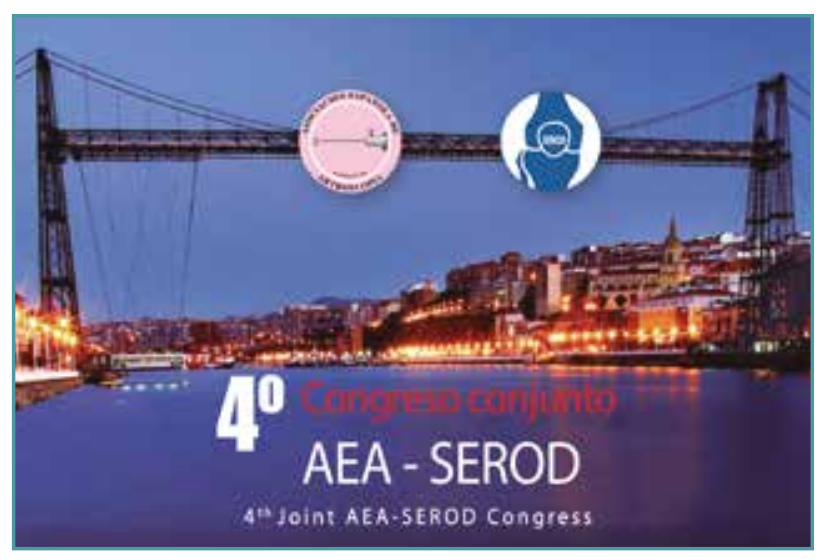

Figura 53. IV Congreso Conjunto AEA-SEROD.

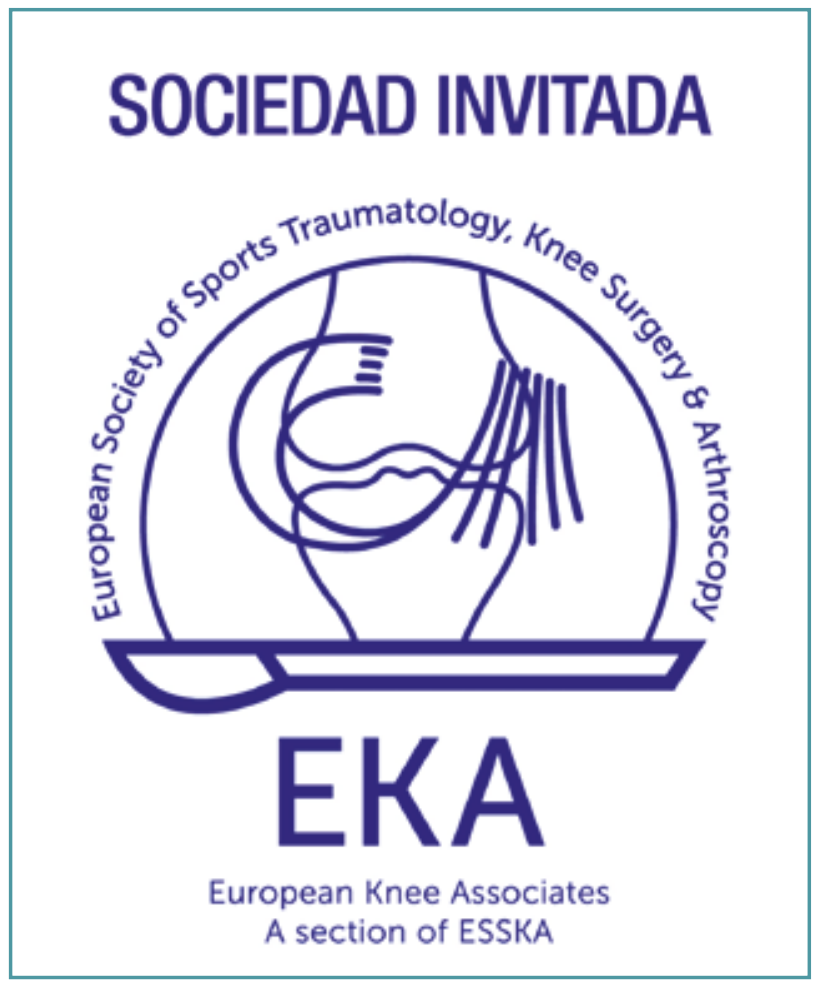

Figura 54. European Knee Associates.

un formato abierto on-line. Con ello, cesa la importante labor de edición desarrollada por Javier Vaquero. La nueva Revista Española de Artroscopia y Cirugía Articular inicia una nueva andadura con la dirección de Eduardo Sánchez Alepuz. Se actualiza la página web y se comienza a participar en las redes sociales.

En esta ocasión, se creó el Premio al Mejor Artículo Publicado en una Revista Indexada. En

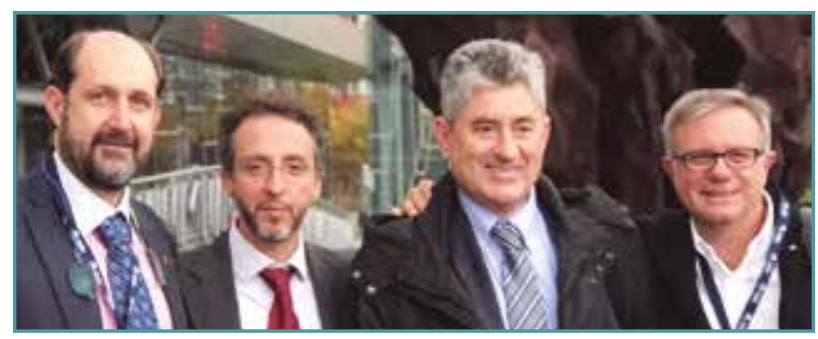

Figura 55. De izda. a dcha., Dr. José Antonio Guerrero, Dr. Sergi Sastre, Dr. Ricardo Cuéllar y Dr. Eduardo Sánchez Alepuz.

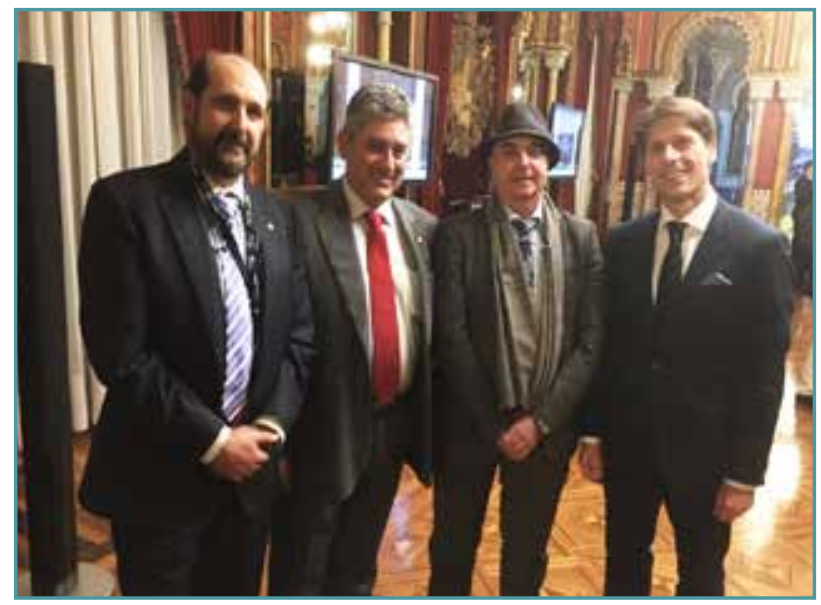

Figura 56. De izda. a dcha., Dr. José Antonio Guerrero, Dr. Ricardo Cuéllar, Dr. Francisco Maculé y Dr. Roland Becker.

memoria de nuestro fallecido presidente, el galardón se ha denominado por ello Premio Rafael Canosa desde esta edición.

El III Congreso Conjunto AEA-SEROD se desarrolló en Madrid en 2015 (Figura 51A), con la presidencia del Comité Organizador del Dr. Manuel Leyes (Figura 51B) y, como Presidente de Honor, el Dr. Pedro Guillén García. Un total de 34 ponentes extranjeros de 10 países diferentes dieron un alto nivel a las charlas y ponencias de este congreso. La sociedad invitada para la ocasión fue The Warthog Society (Figura 51C). El alto nivel de ponencias fue logrado con expertos como van Dijk (Figura 52A), D’Angelo, Matteo Denti, Víctor Ilizaliturri, Dantas, Espregueira (Figura 52B), Barrett, Jackson, Damian Griffin, Jordi Vega o John Bergfeld (Figura 52C).

El IV Congreso Conjunto AEA-SEROD se celebró en noviembre de 2016, en Bilbao (Figura 53). En este año, se retrasó la fecha del mismo por la coincidencia del Congreso Bianual de la ESSKA, ce- 


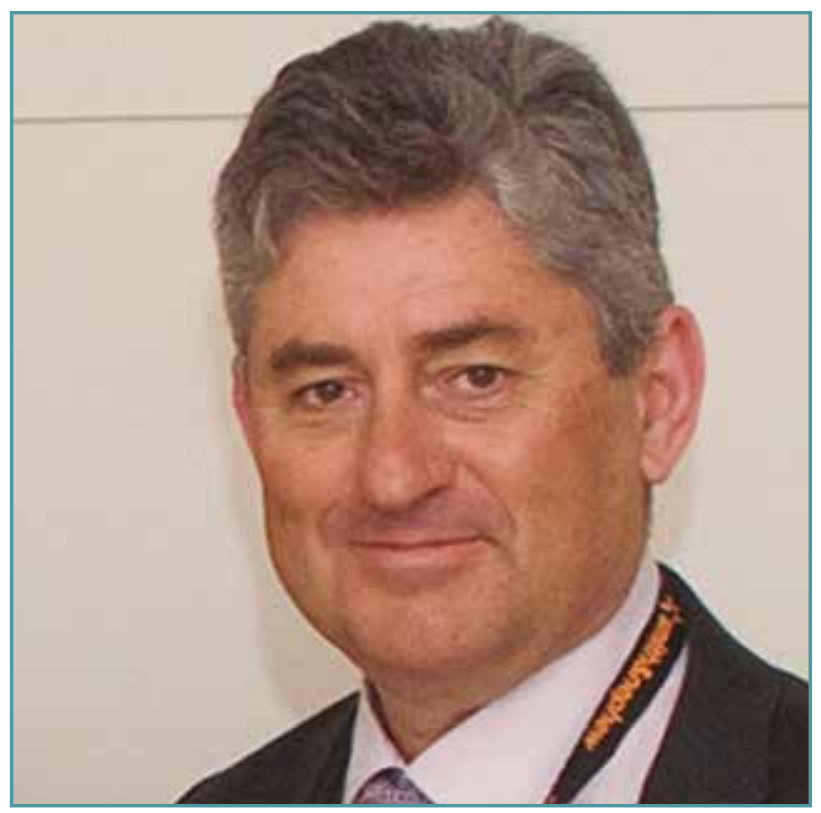

Figura 57. Dr. Ricardo Cuéllar.

lebrado en mayo de 2016 en Barcelona. La sociedad invitada este año fue la European Knee Associates (EKA) (Figura 54). La presidencia de la organización estuvo dirigida por José Antonio Guerrero, siendo Presidente de Honor el Dr. Manuel Martín Montes, figura clave en la artroscopia de la ciudad. El Comité Coordinador entre las dos sociedades se formó con los Dres. Ricardo Cuéllar, Pedro Hinarejos, Elvira Montáñez, Rafael Otero y Juan Ramón Valentí (Figuras 55 y 56). En este congreso se entregaron los primeros diplomas del Plan Nacional de Formación en Artroscopia (PNFA), que fue fruto del esfuerzo de varias juntas de la asociación y del trabajo de decenas de miembros que aportaron sus conocimientos y tiempo en todas las áreas quirúrgicas. La elección del nuevo presidente recayó sobre Ricardo Cuéllar (Figura 57) por el periodo 2016-2018. También cesa en su cargo de director de la revista (REACA), tras alcanzar la vicepresidencia de nuestra sociedad, el Dr. Eduardo Sánchez Alepuz. Es relevado en esta responsabilidad por Manuel Leyes.

Y llegamos a la edición XXXV del Congreso de la AEA y XXVI de Enfermería, que se celebra en mayo de 2017 en Alicante (Figura 58). Con la organización a cargo de Jesús Más (Figura 59), estamos seguros de que será todo un éxito, por sus grandes capacidades de organización y científicas. Celebramos nuestro 35 aniversario de fundación y la sociedad invitada será en esta ocasión

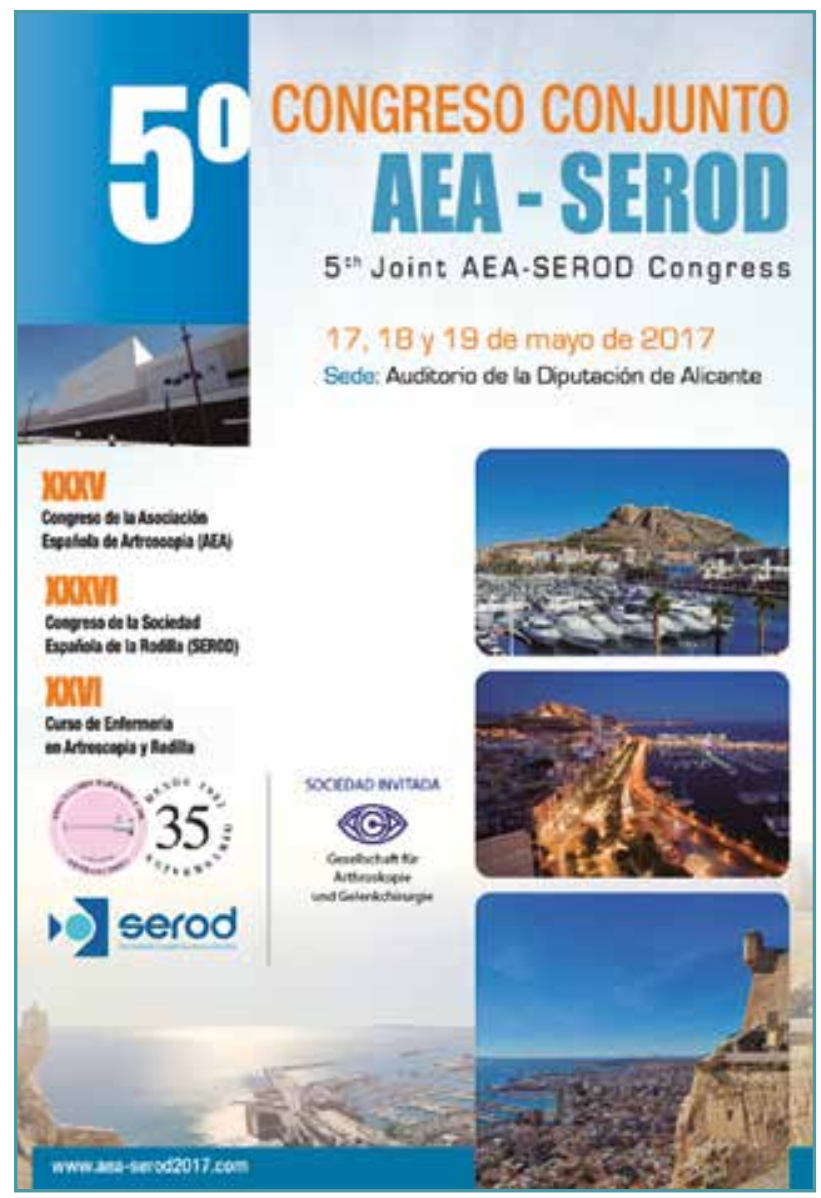

Figura 58. V Congreso Conjunto AEA-SEROD.

la AGA alemana. Por la coincidencia de fechas, se celebrará una mesa redonda conjunta con la SETRADE aprovechando por primera vez las nuevas tecnologías de retransmisión digital (streaming). Aprovechando las mismas, se desarrollará también una mesa redonda conjunta con la Sociedad Latinoamericana de Artroscopia, Rodilla y Deporte (SLARD), que será difundida a los países que se integran en la misma. En memoria de uno de nuestros más admirados compañeros, se crea también este año por primera vez el premio a la mejor fotografía publicada en nuestra revista. El galardón se ha denominado Premio Pau Golanó.

Leyendo estas líneas, hemos llegado a la época contemporánea. Sí, en este 2017 la AEA cumple 35 años y el congreso de Alicante será sin duda un gran evento para la sociedad de "artroscopistas españoles". Entramos en una nueva fase en la que la entrada en vigor de las nuevas normas de justa competencia que regirán para las em- 


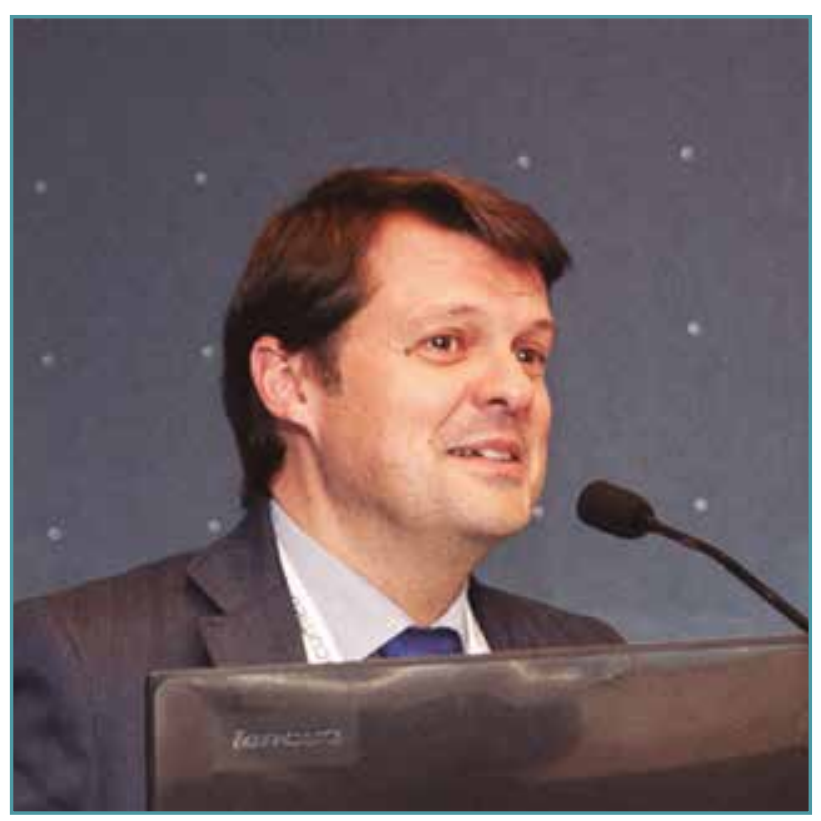

Figura 59. Dr. Jesús Más. presas farmacéuticas y de instrumentales y efectos quirúrgicos, así como las relaciones con otras sociedades afines, como la SEROD, marcarán sin duda de forma importante el desarrollo futuro de nuestros congresos.

En un momento tan especial como es este 35 aniversario, queremos proponer simplemente un recuerdo para los que fueron AEA y partieron: José García Cugat, Luis Munuera, Pepe Díaz, José Juan Muñoz Boira, Xavier Juan Segarra, Raúl Puig Adell, Galán Gallego, Carlos Selas, Rafa Canosa, Pau Golanó..., entre otros anónimos que no por eso son menos importantes. También dedicamos un recuerdo para los que ayudaron a formarnos y tampoco están, Richard B. Caspari, Edward Bittar, Bob Jackson, Hiroshi Ikeuchi: gracias. Y para todos ¡muchas felicidades!

Agradecimientos a Antonia Nogales de la Fundación Española de Artroscopia por su colaboración en la recopilación de gran parte del material gráfico. 